\title{
The genus Pluteus (Basidiomycota, Agaricales, Pluteaceae) from Republic of São Tomé and Príncipe, West Africa
}

\author{
Desjardin $\mathrm{DE}^{1}$ and Perry $\mathrm{BA}^{2}$
}

${ }^{1}$ Department of Biology, San Francisco State University, 1600 Holloway Ave., San Francisco, California 94132, USA ${ }^{2}$ Department of Biological Sciences, California State University East Bay, 25800 Carlos Bee Blvd., Hayward, California 94542, USA

Desjardin DE, Perry BA 2018 - The genus Pluteus (Basidiomycota, Agaricales, Pluteaceae) from Republic of São Tomé and Príncipe, West Africa. Mycosphere 9(3), 598-617, Doi 10.5943/mycosphere/9/3/10

\begin{abstract}
Six species of Pluteus are reported from the African island nation, Republic of São Tomé and Príncipe. Two represent new species ( $P$. hirtellus, $P$. thomensis) and the other four represent new distribution records. Comprehensive descriptions, line drawings, colour photographs, comparisons with allied taxa, a dichotomous key to aid identification, and a phylogenetic analysis of pertinent Pluteus species based on ITS rDNA sequence data are provided.
\end{abstract}

Key words - 2 new species - fungal diversity - Gulf of Guinea - mushrooms - pluteoid fungi taxonomy

\section{Introduction}

In April 2006 (2 weeks) and April 2008 (3 weeks), expeditions led by scientists from the California Academy of Sciences and joined by mycologists from San Francisco State University visited the West African islands of São Tomé and Príncipe to document the diversity of plants, amphibians, marine invertebrates and macrofungi. This is the sixth in a series of papers focused on documenting the basidiomycetous macrofungi from the Republic (Desjardin \& Perry 2009, 2015a, b, 2016, 2017).

The genus Pluteus Fr. (Pluteaceae, Agaricales), comprising about 300 species, is quite common in tropical habitats. Most species grow on well-decayed wood and are characterized by basidiomes with free lamellae, pinkish brown, non-ornamented, inamyloid basidiospores, and convergent hymenophoral trama (Singer 1986). We follow the infrageneric classification of Justo et al. (2011a, b) in recognizing three sections, Pluteus, Celluloderma Fayod and Hispidoderma Fayod. Prior to this accounting, no species of Pluteus have been reported from the Republic of São Tomé and Príncipe. Geographically, the closest species have been reported from the Democratic Republic of Congo (Beeli 1928, Horak 1977, 1978, Menolli et al. 2014), several of which are recognized herein from São Tomé and Príncipe. We describe, illustrate, and compare six species of Pluteus from the Republic, based on morphological and molecular (ITS sequences) data. Two of these represent new species, while the other four are new distributional records.

\section{Materials \& Methods}

Specimens were dried on a $\mathrm{Nesco}^{\circledR}$ food dehydrator, packed in airtight plastic bags and hand 
carried back to the USA. Macromorphological data were derived from fresh specimens, whereas micromorphological data were derived from dried specimens rehydrated in ethanol followed by distilled water, $3 \% \mathrm{KOH}$ or Melzer's reagent. Colour terms and notations are those of Kornerup \& Wanscher (1978). Basidiospore statistics include: $\mathrm{x}_{\mathrm{m}}$, the arithmetic mean of the spore length by spore width ( \pm standard deviation) for $\mathrm{n}$ spores measured in a single specimen; $\mathrm{x}_{\mathrm{mr}}$, the range of spore means, and $x_{\mathrm{mm}}$, the mean of spore means $( \pm \mathrm{SD})$ when more than one specimen is available; $\mathrm{Q}$, the quotient of spore length by spore width in any one spore, indicated as a range of variation in $\mathrm{n}$ spores measured; $\mathrm{Q}_{\mathrm{m}}$, the mean of $\mathrm{Q}$-values in a single specimen; $\mathrm{Q}_{\mathrm{mr}}$, the range of $\mathrm{Q}_{\mathrm{m}}$ values and $\mathrm{Q}_{\mathrm{mm}}$, the mean of $\mathrm{Q}_{\mathrm{m}}$ values where more than one specimen is available; $\mathrm{n}$, the number of spores measured per specimen; s, the number of specimens involved. In the line drawings, cross-hatching represents pigmented cell contents. All cited specimens are deposited in the H.D. Thiers Herbarium, Dept. of Biology, San Francisco State University (SFSU).

Total genomic DNA was extracted from dried material using the Extract-N-Amp Plant PCR Kit (Sigma-Aldrich, St. Louis, MO) following the manufacturer instructions. PCR protocols followed those outlined in Perry et al. (2007). For all species included, the nuclear ribosomal internal transcribed spacer region (ITS) was amplified using primers ITS1-F/ITS4 (Gardes \& Bruns 1993, White et al. 1990). Amplification products were cleaned using the Exo-SAPit kit (Affymetrix, Santa Clara, CA), and sent to Elim Biopharmaceuticals (Hayward, CA) for sequencing with the same primer pairs used for amplification. Resulting sequencing products were edited and assembled in Geneious 9.0 (Biomatters Ltd., Auckland, New Zealand). All ITS sequences generated as part of this study have been deposited in GenBank (accessions MG968798MG968804).

To further investigate the taxonomic affinities of the African material referable to the genus Pluteus, ITS sequences were analyzed phylogenetically within a broad sample of the genus. Sequence data obtained from the African collections, as well as supplemental sequences downloaded from GenBank, were aligned within the existing datasets of Justo et al. (2011a) for Pluteus sections Celluloderma, Hispidoderma and Pluteus, which are available from TreeBase.org. All alignments were manually edited in Mesquite (Maddison \& Maddison 2015). Maximum likelihood analyses were run in RAxML 8.2.9 (Stamatakis 2014) under a GTRGAMMAX model and consisted of 100 alternative runs using the default parameters, with node support estimated by 100 RAxML bootstrap replicates. Bayesian analyses were performed within the CIPRES Science Gateway (Miller et al. 2010), using Metropolis Coupled MCMC methods as implemented in MrBayes 3.2.6 (Huelsenbeck \& Ronquist 2001, Ronquist \& Huelsenbeck 2003) under an $\mathrm{HKY}+\mathrm{I}+\mathrm{G}$ (sect. Celluloderma) or $\mathrm{GTR}+\mathrm{I}+\mathrm{G}$ (sects. Hispidoderma and Pluteus) models of sequence evolution as determined under the Bayesian Information Criterion in PAUP* 4.0a.159 (Swofford 2002). Bayesian analyses consisted of two parallel searches, run for 12 million generations and initiated with random starting trees, and default chain temperature and swaps per generation parameters. Eight chains were sampled every 1200 generations for a total of 1001 trees each, sampled from the posterior distribution. Those trees sampled prior to the runs reaching an average standard deviation of split frequencies of 0.01 were discarded as the burn-in, while the remaining trees were used to calculate the posterior probabilities of the individual clades. Default settings were used in MrBayes to set unconstrained branch lengths and uninformative topology priors. The aligned ITS datasets and associated tree files have been deposited in TreeBase (http://purl.org/phylo/treebase/phylows/study/TB2:S22346?x-access-

code $=\mathrm{e} 12 \mathrm{~b} 54 \mathrm{e} 6 \mathrm{c} 68 \mathrm{cf} 59 \mathrm{~b} 9 \mathrm{fe} 606 \mathrm{f} 2395 \mathrm{~b} 5 \mathrm{~d} 83 \&$ format $=\mathrm{html})$.

\section{Results}

Based on a combination of morphological and molecular (ITS sequences) characters, the six species of Pluteus from São Tomé and Príncipe belong to three infrageneric sections. Within sect. Hispidoderma, $P$. albidus belongs to the longistriatus clade of Justo et al. (2011a), while $P$. chrysaegis and $P$. thomensis belong to the leoninus clade (Fig. 1). In sect. Pluteus, P. albostipitatus belongs to the albostipitatus clade, sister to P. salicinus, while P. losulus belongs to the losulus 
clade, sister to P. atromarginatus (Fig. 6). Within sect. Celluloderma, P. hirtellus forms a relatively long branch sister to $P$. riberaltensis var. conquistensis in the ephebeus clade (Fig. 11).

\section{Artificial Key to Pluteus of São Tomé and Príncipe}

1. Pileus pure white overall 1. P. albidus

1. Pileus yellow, grey, greyish brown, brown or dark brown 2

2. Pileus yellow, glabrous .............................................................................. 2. P. chrysaegis

2. Pileus grey, greyish brown, brown or dark brown, appressed-fibrillose, fibrillose-punctate, granulose or shaggy 3

3. Pleurocystidia thick-walled, at least some of them cornute, with apical horns; pileipellis a cutis with undifferentiated terminal cells 4

3. Pleurocystidia thin-walled, lacking apical horns; pileipellis a cutis to trichodermium with differentiated, fusoid to fusoid-ventricose terminal cells 5

4. Clamp connections absent; only some pleurocystidia cornute, apical horns often bifid; pileus distinctly striate, disc fibrillose-punctate to granulose 4. P. albostipitatus 4. Clamp connections present; all pleurocystidia cornute, apical horns conical; pileus non-striate, radially streaked, appressed-fibrillose

5. P. losulus

5. Pileus surface granulose, radially wrinkled; basidiospores subglobose to broadly ellipsoid $(\mathrm{Q}=$ 1.1-1.3), mean $6.8 \times 5.8 \mu \mathrm{m}$; pileipellis a trichodermium of erect terminal cells ...... 3. P. thomensis 5. Pileus surface shaggy, with tiny fibrillose scales; basidiospores globose to subglobose $(\mathrm{Q}=1.0$ 1.1 ), mean $5.3 \times 5 \mu \mathrm{m}$; pileipellis a cutis to trichodermium with clustered to scattered, erect to repent terminal cells 6. P. hirtellus

\section{Taxonomy}

\section{Sect. Hispidoderma Fayod}

Pluteus albidus Beeli, Bull. Soc. R. Bot. Belg. 61(1): 82. 1928.

Fig. 2 non Pluteus albidus Pegler, Kew Bull., Addit. Ser. 6: 267. 1977 (nom. illeg., Art. 53.1)

Facesoffungi number: FoF04778

Pileus 10-25 $\mathrm{mm}$ diam, obtusely conical-umbonate to campanulate, expanding to broadly convex with a small umbo, pellucid-striate; surface dull, dry, disc minutely granulose when young, glabrous in age, pure white overall. Context $<1 \mathrm{~mm}$ thick, soft, white. Lamellae free, close with 1-2 series of lamellulae, broad (2-3 mm), white when young, soon pink (7A2-3). Stipe 13-34 × 1-2 $\mathrm{mm}$, central, terete, cylindrical above a subbulbous base, solid to stuffed; surface dull, dry, pruinose, white, base with white tomentum. Odor indistinct.

Basidiospores 6.4-8 $\times 5.4-7 \mu \mathrm{m}\left[\mathrm{x}_{\mathrm{m}}=6.9 \pm 0.52 \times 6.0 \pm 0.49 \mu \mathrm{m}, \mathrm{Q}=1.0-1.2, \mathrm{Q}_{\mathrm{m}}=1.14 \pm\right.$ $0.02, \mathrm{n}=30, \mathrm{~s}=1]$, subglobose, smooth, hyaline, inamyloid, walls up to $0.5 \mu \mathrm{m}$ thick. Basidia $23-$ $28 \times 7-8.5 \mu \mathrm{m}$, narrowly utriform, 4-spored, unclamped. Basidioles clavate. Lamellar edge sterile. Cheilocystidia 32-48 × 11-20 (-24) $\mu \mathrm{m}$, versiform, broadly clavate, ventricose, broadly fusiform or sublageniform, hyaline, inamyloid, thin-walled. Pleurocystidia 37-54 × 11-20 (-23) $\mu \mathrm{m}$, broadly clavate-mucronate to broadly fusiform, seldom broadly clavate, hyaline, inamyloid, thin-walled. Pileipellis a cutis with scattered to clustered, repent to erect terminal cells (pileocystidia); hyphae 4.5-9 $\mu \mathrm{m}$ diam, cylindrical, hyaline, inamyloid, non-incrusted, non-gelatinous, thin-walled; terminal cells $56-100 \times 16-28 \mu \mathrm{m}$, subcylindrical to clavate or ventricose, hyaline, thin-walled. Pileus trama loosely interwoven; hyphae 4-20 $\mu \mathrm{m}$ diam, cylindrical, hyaline, inamyloid, nonincrusted, non-gelatinous, thin-walled. Lamellar trama hyphae 2.5-19 $\mu \mathrm{m}$ diam, similar to pileus trama hyphae. Stipitipellis a cutis with scattered caulocystidia; hyphae 3-10 $\mu \mathrm{m}$ diam, cylindrical, hyaline, inamyloid, non-incrusted, non-gelatinous, thin-walled. Caulocystidia 28-64 × 8-24 $\mu$ m, similar to the pileipellis terminal cells, clavate to ventricose. Clamp connections absent. 
Habitat and known distribution - Solitary on woody branches or on trunk of standing dead tree in primary forest. Africa (DR Congo, São Tomé).

Material examined - AFRICA. São Tomé, Parque Nacional Obo, trail to Lagoa Amelia, between $\mathrm{N} 00^{\circ} 17.112^{\prime}, \mathrm{E}^{\circ} 6^{\circ} 35.767^{\prime}$ and N00 ${ }^{\circ} 16.922^{\prime}, \mathrm{E}^{\circ} 6^{\circ} 36.062,14$ April 2008, coll. by B.A. Perry, BAP 612 (MG968798, SFSU); same location, 28 April 2006, coll. by D.E. Desjardin (material lost).

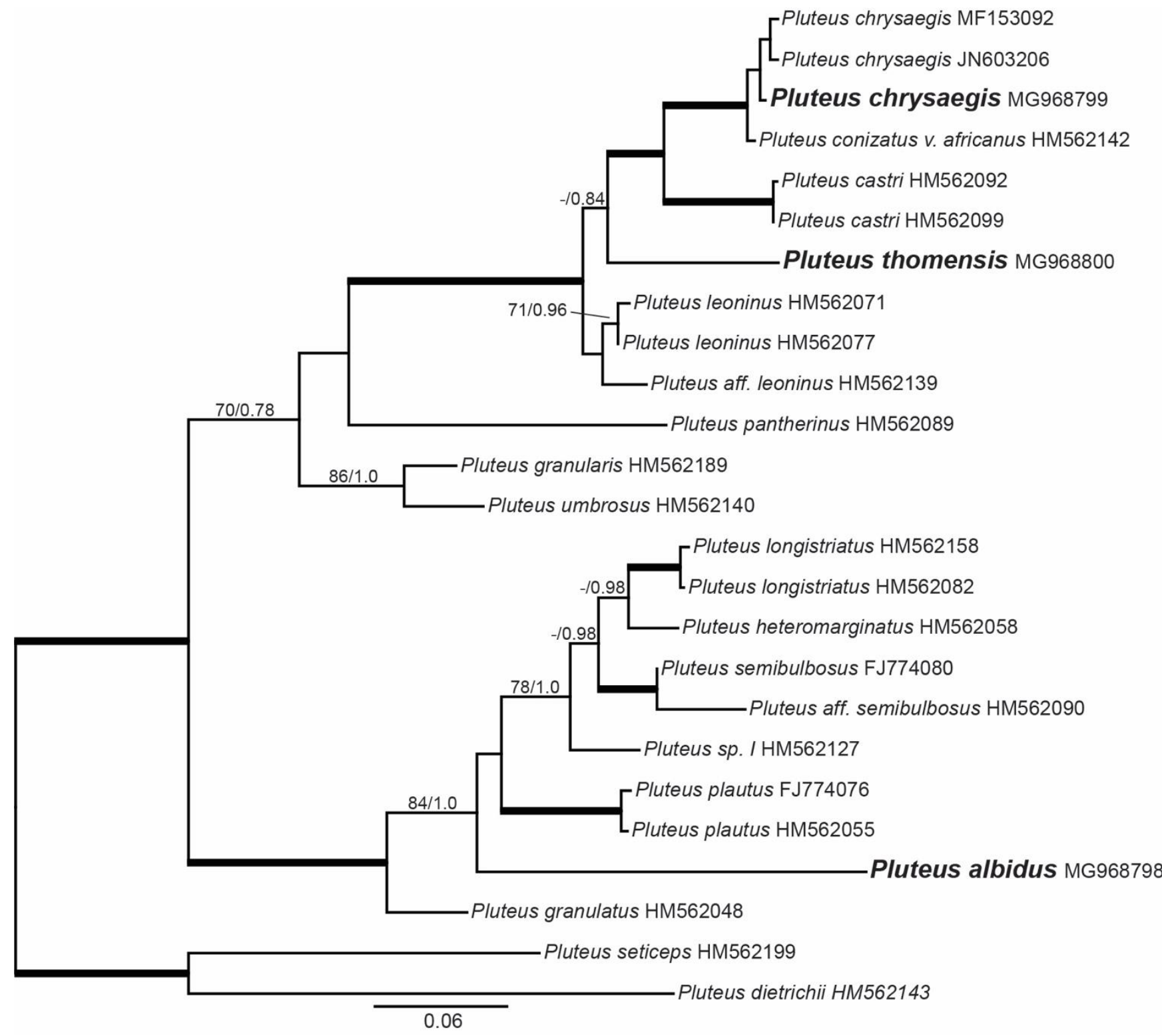

Figure 1 - Maximum likelihood phylogeny of Pluteus sect. Hispidoderma based on ITS sequence data $(-\ln L=4341.716170)$. Sequences of species from São Tomé are indicated in bold type. Values separated by/refer to nonparametric ML bootstrap proportions and Bayesian posterior probabilities. Only values greater than $70 / 0.70$ are shown (- designates a value below $70 \%$ or 0.70 ). Nodes receiving support values greater than 90/0.95 are highlighted in bold.

Notes - Pluteus albidus is characterized by small white basidiomes with conical-umbonate pileus, broad lamellae, pruinose, subbulbous stipe, subglobose basidiospores with mean $6.9 \times 6 \mu \mathrm{m}$, versiform cheilocystidia, thin-walled, broadly clavate-mucronate to broadly fusiform pleurocystidia, a cutis-type pileipellis with clavate to ventricose terminal cells $16-28 \mu \mathrm{m}$ diam, scattered caulocystidia similar to the pileocystidia, an absence of clamp connections, and growth on woody debris. The protologue (Beeli 1928), based on a collection from the DR Congo, matches 
quite nicely the material from São Tomé. In combination, these features indicate placement in sect. Hispidoderma. Interestingly, Pegler's (1977) illegitimate homonym $P$. albidus, based on a specimen from Tanzania, may represent the same species. His material differs only subtly from our São Tomé specimen in forming a convex-depressed (not umbonate) pileus, and he did not report the presence of clavate to ventricose pileipellis terminal cells and caulocystidia. White forms of Pluteus plautus (Weinm.) Gillet are similar in basidiospore size, and cystidium shape and size (Vellinga \& Schreurs 1985, Vellinga 1990), but the later species forms a hymeniderm-type pileipellis, quite different from the cutis-type pileipellis of P. albidus.

Pairwise comparisons of aligned, overlapping ITS sequences of $P$. albidus (BAP 612) with the top ten BLAST results indicate closest similarity of $95.1 \%$ to an undetermined Pluteus species from New Zealand (KU131676) and 90.0-92.6\% similarity to eight other undetermined Pluteus. In our ITS phylogenetic analyses (Fig. 1), P. albidus fell into sect. Hispidoderma, on a long branch inside a well-supported clade (100\% BS, 1.0 PP) with P. granulatus, $P$. plautus, $P$. semibulbosus, $P$. heteromarginatus and $P$. longistriatus.

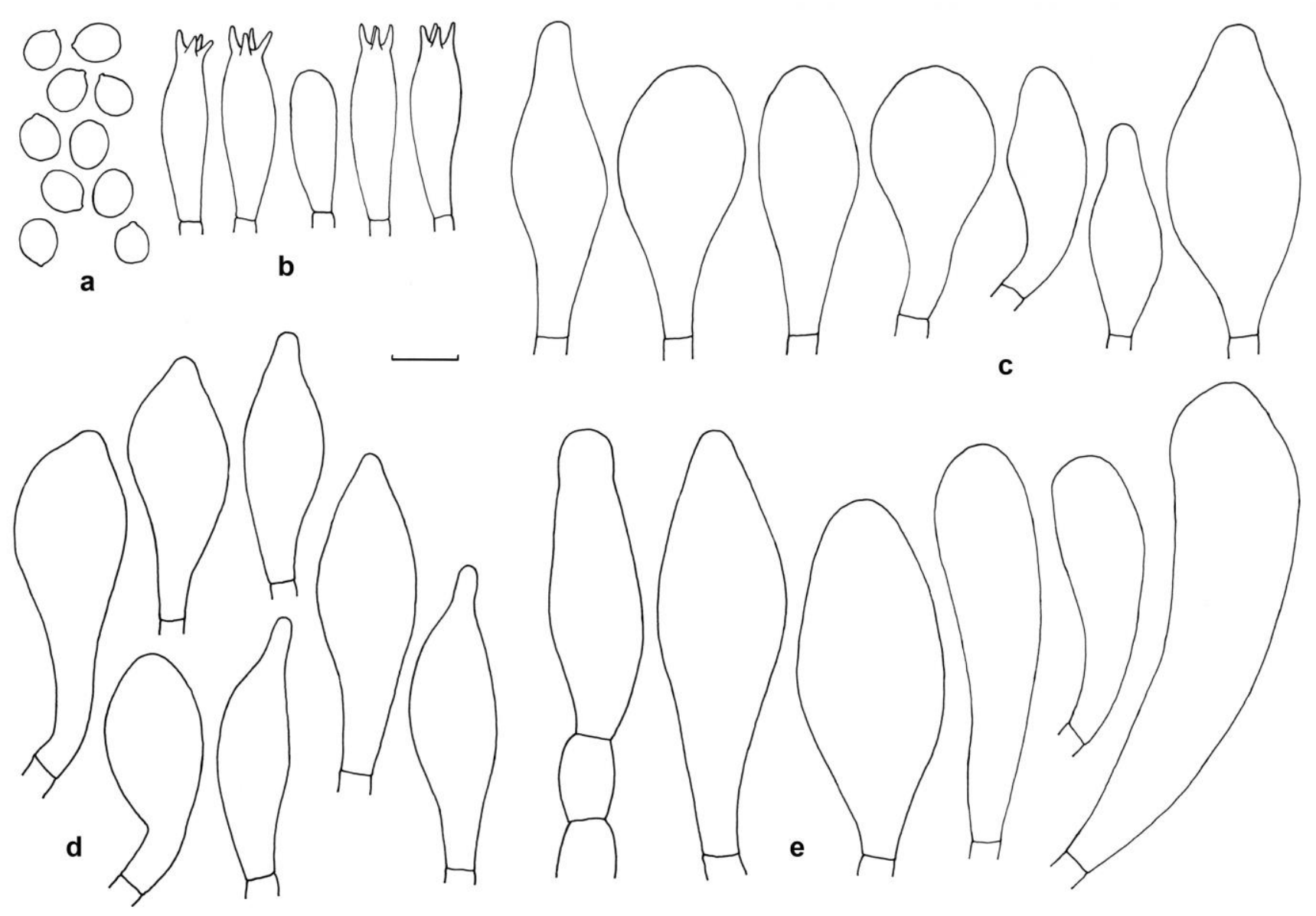

Figure 2 - Micromorphological features of Pluteus albidus (BAP 612). a Basidiospores. b Basidia and basidiole. c Cheilocystidia. d Pleurocystidia. e Pileipellis terminal cells. Scale bar $=10 \mu \mathrm{m}$

Pluteus chrysaegis (Berk. \& Broome) Petch, Ann. R. Bot. Gdns Peradeniya 5(4): 271. 1912.

Figs 3-4

Basionym: Agaricus chrysaegis Berk. \& Broome, J. Linn. Soc., Bot. 11(56): 536. 1871.

= Entoloma chrysaeges (Berk. \& Broome) Sacc., Syll. Fung, (Abellini) 5: 61. 1887.

Facesoffungi number: FoF04780

Pileus 20-24 $\mathrm{mm}$ diam, plano-convex, expanding to plane-depressed, striate half way to center, disc smooth; surface dull, moist to dry, glabrous; disc greyish yellow (3B4-5, 4C6-7), margin yellow (3A3-5) to yellowish white (3A2). Context $1 \mathrm{~mm}$ thick, white. Lamellae horizontal, 
free, close with 2-3 uneven series of lamellulae, broad (2-3 mm), pale pink to pale pinkish brown (9A-B3). Stipe $22-23 \times 1.5-2.0 \mathrm{~mm}$, central, terete, cylindrical above a subbulbous base, solid, curved; surface dull, dry, minutely pruinose; apex white to dingy buff, base pale greyish pink (7B2-3) to dingy pink (8A2-3). Odor indistinct.

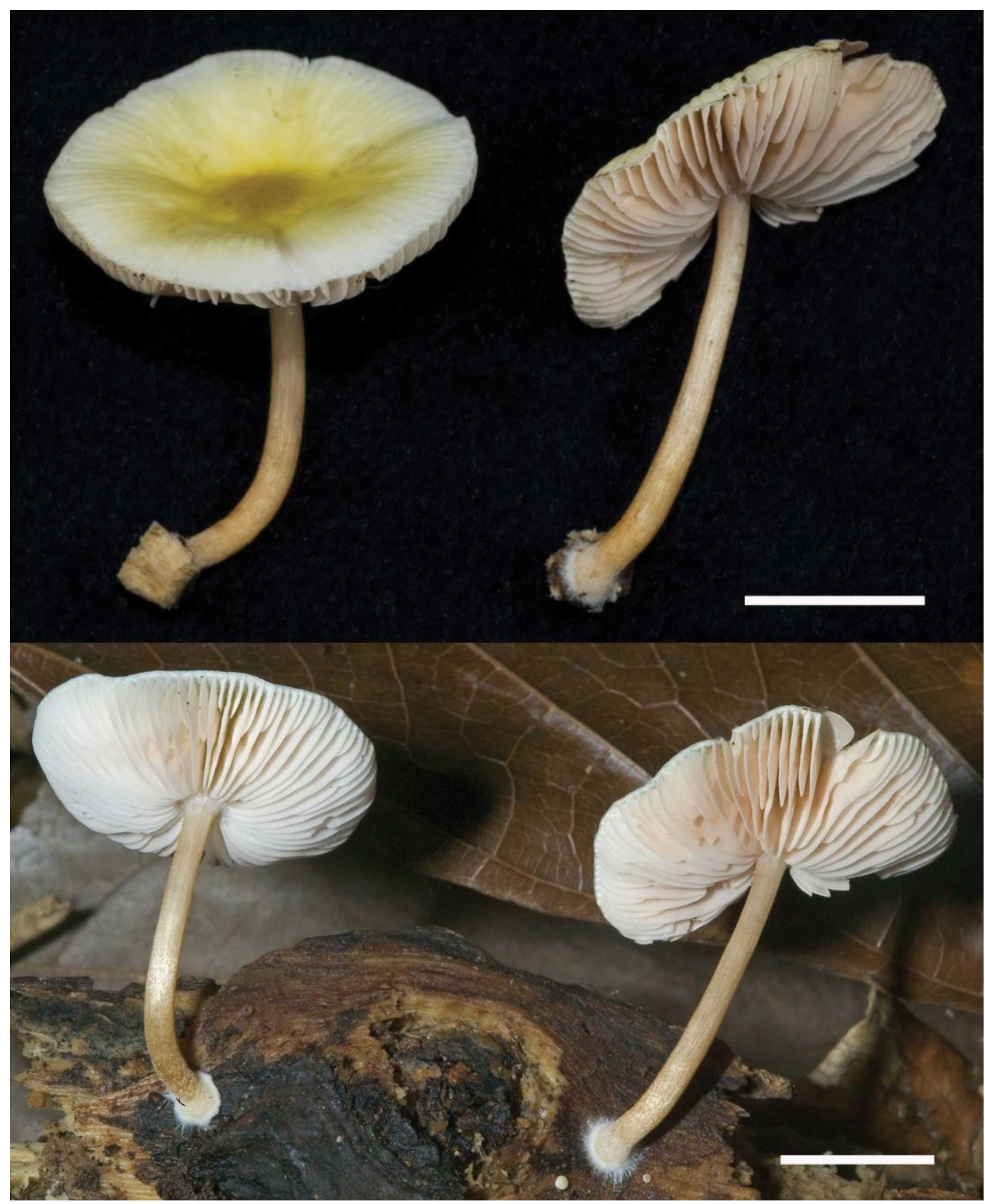

Figure 3 - Basidiomes of Pluteus chrysaegis (DED 8226). Scale bar $=10 \mathrm{~mm}$

Basidiospores 5.2-6 $\times 4.5-5.5 \mu \mathrm{m}\left[\mathrm{x}_{\mathrm{m}}=5.6 \pm 0.22 \times 5.0 \pm 0.25 \mu \mathrm{m}, \mathrm{Q}=1.0-1.2, \mathrm{Q}_{\mathrm{m}}=1.12\right.$ $\pm 0.04, \mathrm{n}=20, \mathrm{~s}=1]$, subglobose to ovoid, smooth, pale golden in $\mathrm{KOH}$, inamyloid, thick-walled, typically uniguttulate. Basidia 25-30 × 6.5-7 $\mu \mathrm{m}$, utriform, 4-spored, unclamped. Basidioles subcylindrical to subclavate. Lamellar edge sterile. Cheilocystidia 22-36 $\times 6.5-9.5 \mu \mathrm{m}$, subfusoid to lageniform, hyaline, thin-walled. Pleurocystidia common, 35-77 $\times 12-24 \mu \mathrm{m}$, lageniform, hyaline, thin-walled or with walls up to $0.6 \mu \mathrm{m}$ thick, especially in central portion of cell. Pileipellis a hymeniderm with pileocystidia; majority of cells $12-20 \times 6.5-12 \mu \mathrm{m}$, broadly clavate to vesiculose, hyaline, thin-walled; pileocystidia $22-36 \times 6.5-10 \mu \mathrm{m}$, subfusoid to lageniform, hyaline, thin-walled. Pileus and lamellar trama hyphae $2.5-16 \mu \mathrm{m}$ diam, cylindrical to inflated, 
hyaline, inamyloid, non-gelatinous, thin-walled. Stipitipellis a cutis; hyphae 7-10 $\mu \mathrm{m}$ diam, cylindrical to slightly inflated, hyaline, inamyloid, non-incrusted, non-gelatinous, thin-walled. Caulocystidia scattered or clustered, 17-32 × 9.5-20 $\mu \mathrm{m}$, broadly clavate to vesiculose, seldom lageniform, hyaline, thin-walled. Clamp connections absent in all tissues.

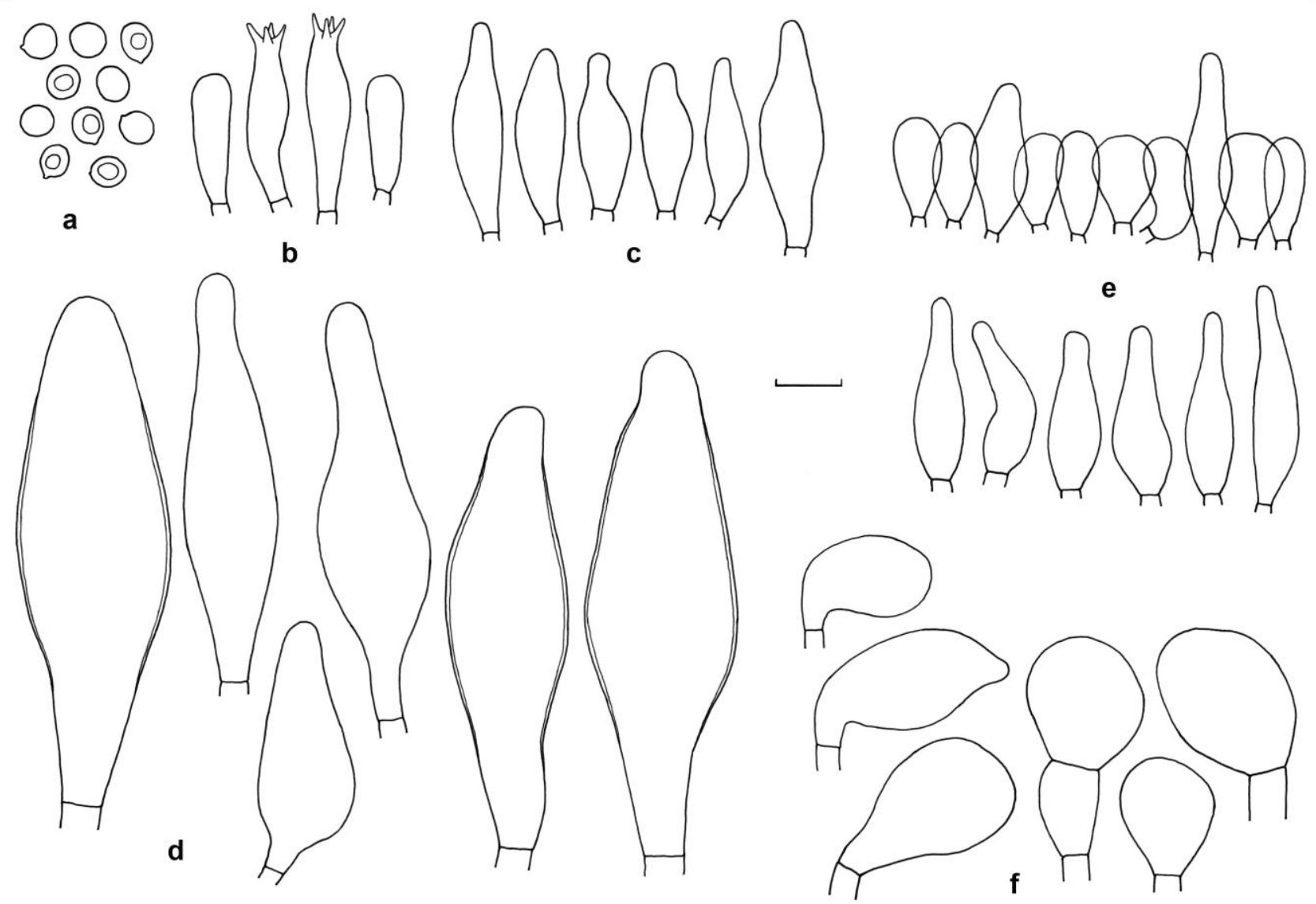

Figure 4 - Micromorphological features of Pluteus chrysaegis (DED 8226). a Basidiospores. b Basidia and basidioles. c Cheilocystidia. d Pleurocystidia. e Pileipellis and pileocystidia. f Caulocystidia. Scale bar $=10 \mu \mathrm{m}$

Habitat and known distribution - Solitary on rotten wood in coastal secondary forest with banana, cacao and coffee. Africa (DR Congo, São Tomé), India, Sri Lanka.

Material examined - AFRICA. São Tomé, along main road (EN-2) on south side of island near $38 \mathrm{~km}$ marker, N0008.500', E06 39.560', 13 April 2008, coll. by D.E. Desjardin, DED 8226 (MG968799, SFSU).

Notes - The São Tomé specimen is distinguished by small basidiomes with yellow, glabrous, striate pileus, a white to pink, pruinose stipe, small subglobose basidiospores with mean $5.6 \times 5$ $\mu \mathrm{m}$, relatively small subfusoid to lageniform, thin-walled cheilocystidia, large lageniform pleurocystidia with thickened walls, a hymeniderm pileipellis with lageniform pileocystidia, broadly clavate caulocystidia, an absence of clamp connections, and growth on rotten wood. In combination, these features indicate placement in sect. Hispidoderma, allied with the leoninus clade.

Pluteus chrysaegis, originally described from Sri Lanka (Berkeley \& Broome 1871), was recently redescribed from material collected in India (Pradeep \& Vrinda 2006, Pradeep et al. 2012). The Indian material differs from the São Tomé specimen in forming more brilliant chrome yellow pileus with an olive brown to coffee-colored, rugulose-venose disc, and has apically thick-walled, acutely fusiform cheilocystidia. Pluteus conizatus var. africanus Horak (1977), described from the DR Congo and accepted as a synonym of P. chrysaegis by Pradeep et al. (2012), has slightly narrower basidiospores $(4-4.5(-5) \mu \mathrm{m})$ and also shows the apically thick-walled, acutely fusoid 
cheilocystidia (Horak 1978) not seen in the São Tomé specimen.

Pairwise comparisons of aligned, overlapping ITS sequences of the São Tomé specimen (DED 8226) with the top ten BLAST results indicate 97.5\% similarity with two sequences of $P$. chrysaegis (JN603206 - India; MF153092 - Florida) and 98.7\% similarity with the sequence of the holotype of $P$. conizatus var. africanus (HM562142). Our phylogenetic analysis of ITS sequences of members of sect. Hispidoderma (Fig. 1) place the São Tomé specimen in a well-supported clade (100\% BS, $1.0 \mathrm{PP}$ ) with $P$. chrysaegis and $P$. conizatus var. africanus, and we recognize this morphologically variable taxon as $P$. chrysaegis.

Pluteus thomensis Desjardin \& B.A. Perry, sp. nov.

Fig. 5

Mycobank: MB824540; Facesoffungi number: FoF04777

Holotype - AFRICA. São Tomé, Macambrara radio antenna area, N00¹6.557', E06 36.326', elev. 1300 m, 25 April 2008, coll. by B.A. Perry, DED 8333 (SFSU). collected.

Etymology - Named in honor of the island São Tomé where the holotype specimen was

Diagnosis - Pileus 16-35 mm diam, broadly convex, expanding to plano-convex with a low, broad umbo, radially wrinkled; surface dull, dry, granulose overall, disc and wrinkles dark brown (7F6-8), margin brown (6E6-8). Context 1-2 mm thick, soft, white. Lamellae free, crowded, broad (3-4 mm), greyish red (7B4). Stipe $24-50 \times 2-2.5 \mathrm{~mm}$, central, terete, cylindrical or gradually enlarged downward to a bulbous or clavate base, solid; surface dull, dry, appressed-silky to pruinose, pale pinkish white (7A2). Odor indistinct.

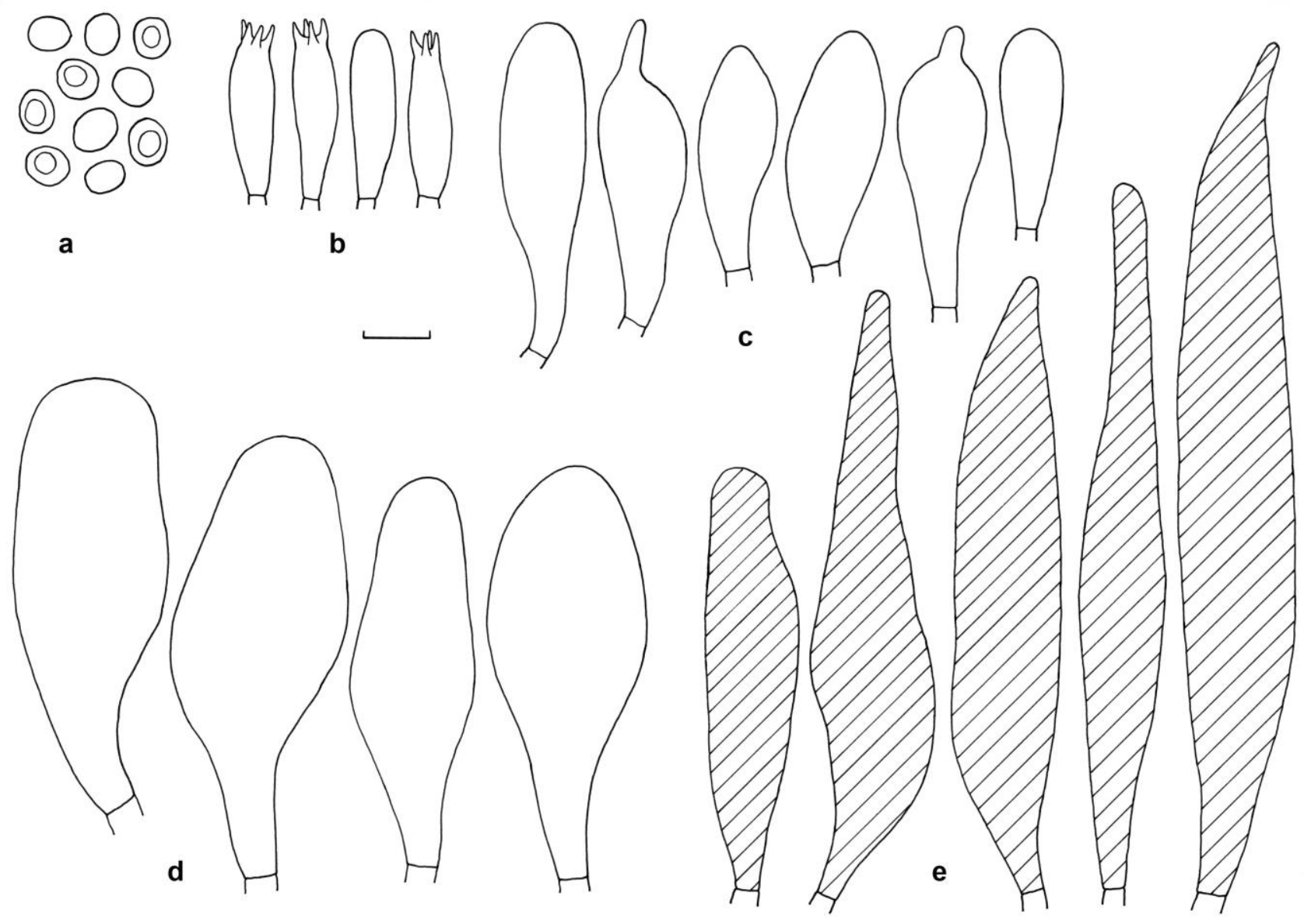

Figure 5 - Micromorphological features of Pluteus thomensis (DED 8333, Holotype). a Basidiospores. b Basidia and basidiole. c Cheilocystidia. d Pleurocystidia. e Pileipellis terminal cells. Scale bar $=10 \mu \mathrm{m}$ 
Basidiospores 6-7.7 $\times 5-6.5 \mu \mathrm{m}\left[\mathrm{x}_{\mathrm{m}}=6.84 \pm 0.42 \times 5.77 \pm 0.30 \mu \mathrm{m}, \mathrm{Q}=1.1-1.3, \mathrm{Q}_{\mathrm{m}}=1.19\right.$ $\pm 0.06, \mathrm{n}=25, \mathrm{~s}=1$ ], subglobose to broadly ellipsoid, smooth, subhyaline, inamyloid, thick-walled $(-0.5 \mu \mathrm{m})$. Basidia 22-26 × 7-8 $\mu \mathrm{m}$, clavate to subutriform, 4-spored, unclamped. Basidioles clavate. Lamellar edge sterile. Cheilocystidia 32-52 × 9.5-16 $\mu \mathrm{m}$, broadly clavate, seldom mucronate, hyaline, thin-walled to firm-walled $(-0.5 \mu \mathrm{m})$. Pleurocystidia scattered, common, 56-70 $\times 16-27 \mu \mathrm{m}$, broadly lageniform to broadly clavate, hyaline, firm-walled $(-0.5 \mu \mathrm{m})$. Pileipellis an interrupted trichodermium of erect, fusiform to clavate cells $60-165 \times 8-24(-32) \mu \mathrm{m}$, acute to subobtuse, hyaline or more commonly with brown cytoplasmic pigments, thin-walled. Pileus trama interwoven; hyphae 3.5-20 $\mu \mathrm{m}$ diam, cylindrical or inflated, hyaline, non-incrusted, nongelatinous, thin-walled. Lamellar trama hyphae 4-14 $\mu \mathrm{m}$ diam, cylindrical, hyaline, non-gelatinous. Stipitipellis a cutis with scattered caulocystidia; hyphae repent, 4-12 $\mu \mathrm{m}$ diam, cylindrical, hyaline, inamyloid, non-incrusted, non-gelatinous, thin-walled. Caulocystidia uncommon, 32-64 × 6.5-11 $\mu \mathrm{m}$, cylindrical, obtuse, hyaline, thin-walled. Clamp connections absent in all tissues.

Habitat and known distribution - Solitary on decaying wood in montane primary forest. Africa (São Tomé).

Material examined - AFRICA. São Tomé, Macambrara radio antenna area, N00 $16.557^{\prime}$, E06 36.326', elev. 1300 m, 25 April 2008, coll. by B.A. Perry, DED 8333 (MG968800, SFSU); São Tomé, between Bom Sucesso at $1170 \mathrm{~m}$ elev. and Lagoa Amelio at $1480 \mathrm{~m}$ elev., near N00 17.317', E06 36.746', 2 May 2006 (material lost in transit).

Notes - Pluteus thomensis is distinguished by relatively small, radially wrinkled, dark brown pileus, a pale pinkish white, solid stipe, subglobose to broadly ellipsoid basidiospores with mean $6.8 \times 5.8 \mu \mathrm{m}$, broadly clavate cheilocystidia, firm-walled, broadly lageniform pleurocystidia, a trichoderm-type pileipellis of large, fusiform to clavate, brown terminal cells, scattered, hyaline, cylindrical caulocystidia, an absence of clamp connections, and growth on rotten wood in a montane primary forest. In combination, these features indicate placement in sect. Hispidoderma.

Pluteus thomensis shows morphological similarities to P. leoninus (Schaeff.) P. Kumm., P. castri Justo \& E.F. Malysheva, P. roseipes Höhn., and P. umbrosus (Pers.) P. Kumm. Pluteus leoninus differs in forming a larger (30-60 mm diam), yellow to yellowish brown pileus, a white to pale yellowish brown stipe, narrowly fusiform cheilocystidia, and pileipellis terminal cells with yellowish contents (Vellinga 1990). Pluteus castri forms a bright yellow to yellowish orange pileus, a cream to yellow stipe, slightly smaller basidiospores (mean $6.1 \times 5 \mu \mathrm{m}$ ), fusiform to lageniform cheilocystidia, and pileipellis terminal cells with yellowish contents (Justo et al. 2011a). Pluteus roseipes has a dark brown, radially wrinkled pileus and solid pink stipe as in $P$. thomensis, but shares similar micromorphology with P. leoninus and grows on conifer wood (Vellinga 1990). Pluteus umbrosus from Europe, is much larger (pileus 55-115 mm diam, stipe 55-120 × 3.5-13 $\mathrm{mm}$ ), forms brown-marginate lamellae, a stipe with dark brown fibrils, smaller basidiospores (5.5$6.5 \times 4-5.5 \mu \mathrm{m}$ ), and hymenial cystidia with brown contents (Vellinga 1990).

Pairwise comparisons of aligned, overlapping ITS sequences of P. thomensis (DED 8333) with the top ten BLAST results indicate closest similarity (89.2\%) to northern California (USA) sequences of $P$. roseipes (KF306003, KC147681) and P. leoninus (KC147682, KC147680). In our phylogenetic analysis of ITS sequences of members of sect. Hispidoderma (Fig. 1), P. thomensis is on a relatively long branch sister to $P$. castri plus $P$. chrysaegis in a well-supported clade (99\% BS, 1.0 PP) with P. leoninus.

\section{Sect. Pluteus Fr.}

Pluteus albostipitatus (Dennis) Singer, Lloydia 21: 240. 1959 (1958).

Figs $7-8$

Basionym: Pluteus spilopus var. albostipitatus Dennis, Bull. Trimest. Soc. Mycol. Fr. 69(2): 195. 1953.

Probable heterotypic synonyms:

= Pluteus phaeoleucus E. Horak, Bull. Jard. Bot. Natn. Belg. 47(1-2): 89. 1977.

= Pluteus densifibrillosus Menolli \& Capelari, Mycologia 102(3): 698. 2010. 


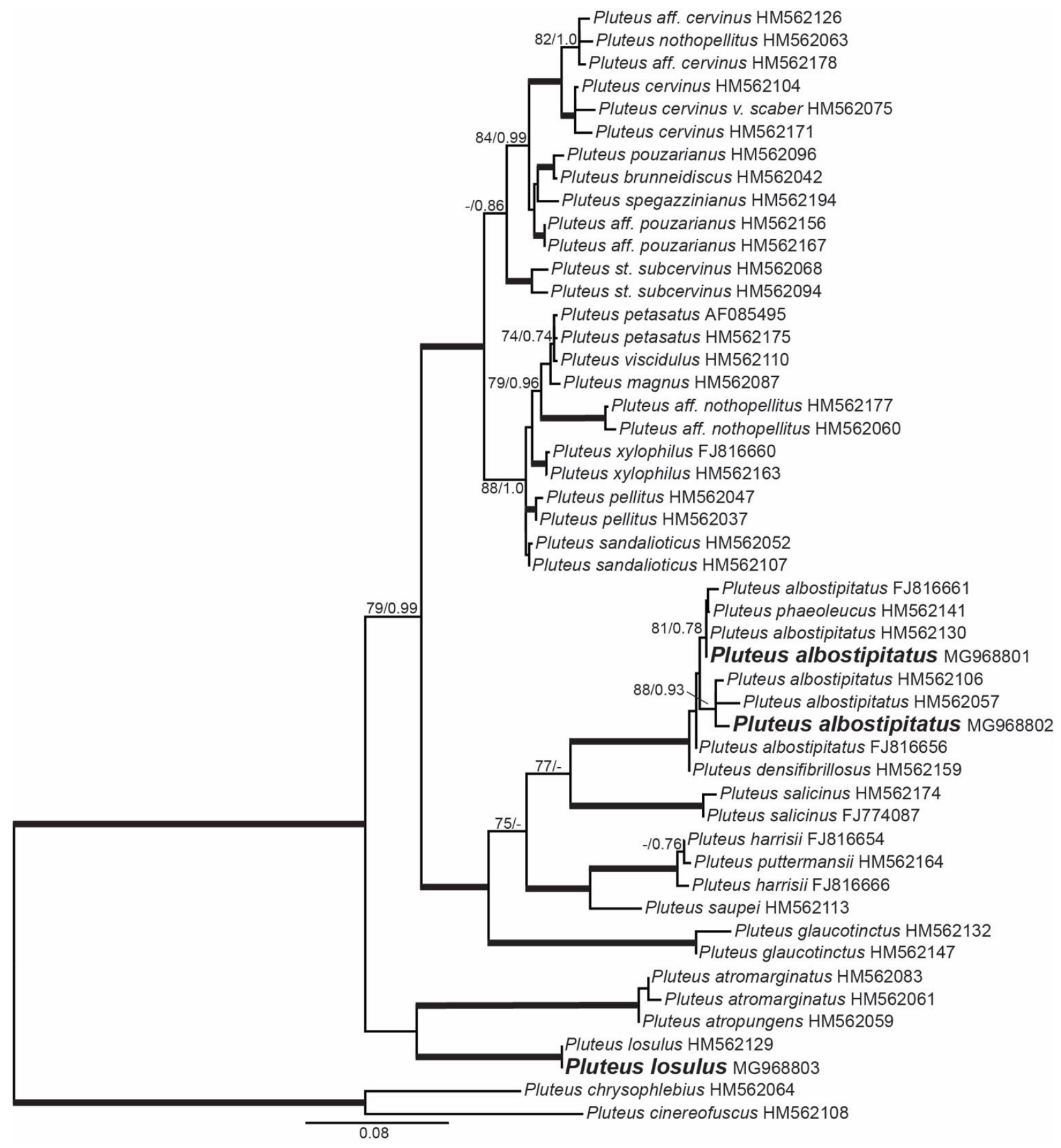

Figure 6 - Maximum likelihood phylogeny of Pluteus sect. Pluteus based on ITS sequence data ($\ln L=4078.335883)$. Sequences of species from São Tomé and Príncipe are indicated in bold type. Values separated by / refer to nonparametric ML bootstrap proportions and Bayesian posterior probabilities. Only values greater than $70 / 0.70$ are shown (- designates a value below $70 \%$ or 0.70 ). Nodes receiving support values greater than 90/0.95 are highlighted in bold.

Facesoffungi number: FoF04779

Pileus 15-50 mm diam, plano-convex, becoming depressed in age, striate nearly to center, margin decurved, weakly folded; surface dull to shiny, moist to dry, disc appressed fibrillosepunctate with black wart-like granules, subglabrous to glabrous elsewhere; disc dark brown (7-8F4-8) to black, margin dark brown (6F4-6) to brown (6E6-8) or greyish brown (6E-F3). Context 1-2 mm thick, soft, white. Lamellae free, close with 2-3 series of lamellulae, broad (3-7 $\mathrm{mm})$, pale pinkish white, becoming greyish red $(8 \mathrm{~B} 3,8 \mathrm{C} 4-5)$ to reddish brown (8D5-6) in age. 
Stipe 15-45 × 2-4 mm, central, terete, cylindrical, solid; surface dull, dry, glabrous to silky, white. Odor indistinct.

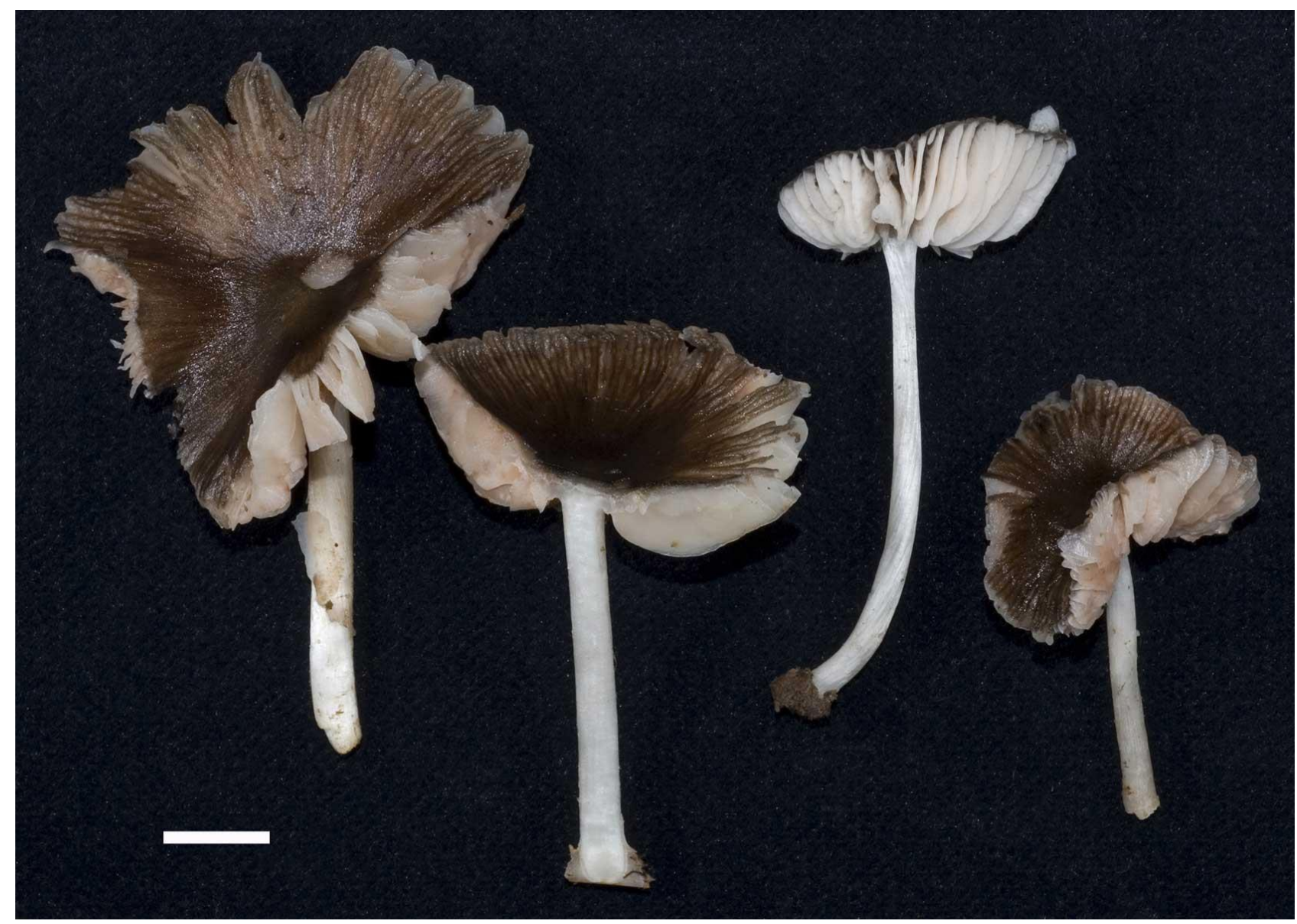

Figure 7 - Basidiomes of Pluteus albostipitatus (DED 8205). Scale bar $=10 \mathrm{~mm}$

Basidiospores 6-8.6 $\times 5.5-7(-8) \mu \mathrm{m}\left[\mathrm{x}_{\mathrm{mr}}=7.2-7.8 \times 6.5-6.6 \mu \mathrm{m}, \mathrm{x}_{\mathrm{mm}}=7.5 \pm 0.44 \times 6.57\right.$ $\pm 0.04 \mu \mathrm{m}, \mathrm{Q}=1.0-1.3, \mathrm{Q}_{\mathrm{m}}=1.14 \pm 0.07, \mathrm{n}=25, \mathrm{~s}=2$ ], subglobose to broadly ellipsoid, rarely globose, smooth, subhyaline, inamyloid, thick-walled $(-0.5 \mu \mathrm{m})$. Basidia 19-36 $\times 7.5-9.5 \mu \mathrm{m}$, clavate to utriform, 4-spored, unclamped. Basidioles subcylindrical to subclavate or ventricose. Lamellar edge sterile. Cheilocystidia 35-64 × 9.5-16 $\mu \mathrm{m}$, broadly clavate, seldom lageniform, hyaline, thin-walled. Pleurocystidia abundant, (48-) 64-100 × 13-25 $\mu \mathrm{m}$, clavate to lageniform, ventricose or fusoid-subcapitate, obtuse and without outgrowths, or corniculate with 4-6 or more small, short horn-like apical outgrowths, sometimes horns bifid, firm- to thick-walled $(0.5-1.5 \mu \mathrm{m})$, often thinning towards the base of cell, hyaline. Pileipellis a cutis of repent hyphae (3-) 4.5-12 $(-16) \mu \mathrm{m}$ diam, cylindrical, with brown cytoplasmic pigments, non-incrusted, non-gelatinous, thinwalled; terminal cells undifferentiated, cylindrical to subclavate, obtuse, clustered and suberect over pileus disc, repent elsewhere. Pileus trama interwoven; hyphae 4.5-16 (-24) $\mu \mathrm{m}$ diam, cylindrical to inflated, hyaline, inamyloid, thin-walled. Lamellar trama hyphae 3.5-12 (-16) $\mu \mathrm{m}$ diam, cylindrical to inflated, hyaline, non-gelatinous, thin-walled. Stipitipellis a cutis; hyphae 3-12 $\mu \mathrm{m}$ diam, cylindrical, hyaline, inamyloid, non-incrusted, non-gelatinous, thin-walled. Caulocystidia absent. Clamp connections absent in all tissues.

Habitat and known distribution - Solitary on very rotten wood of undetermined dicotyledonous tree in montane primary forest, and on rotting coconut palm wood in coastal coconut grove. Africa (DR Congo, São Tomé), Caribbean (Martinique, Trinidad), South America (Argentina, Bolivia, Brazil). 


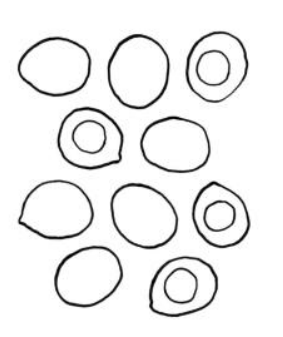

a

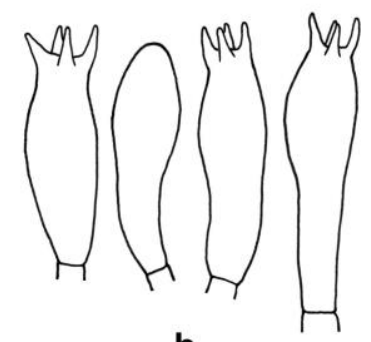

b
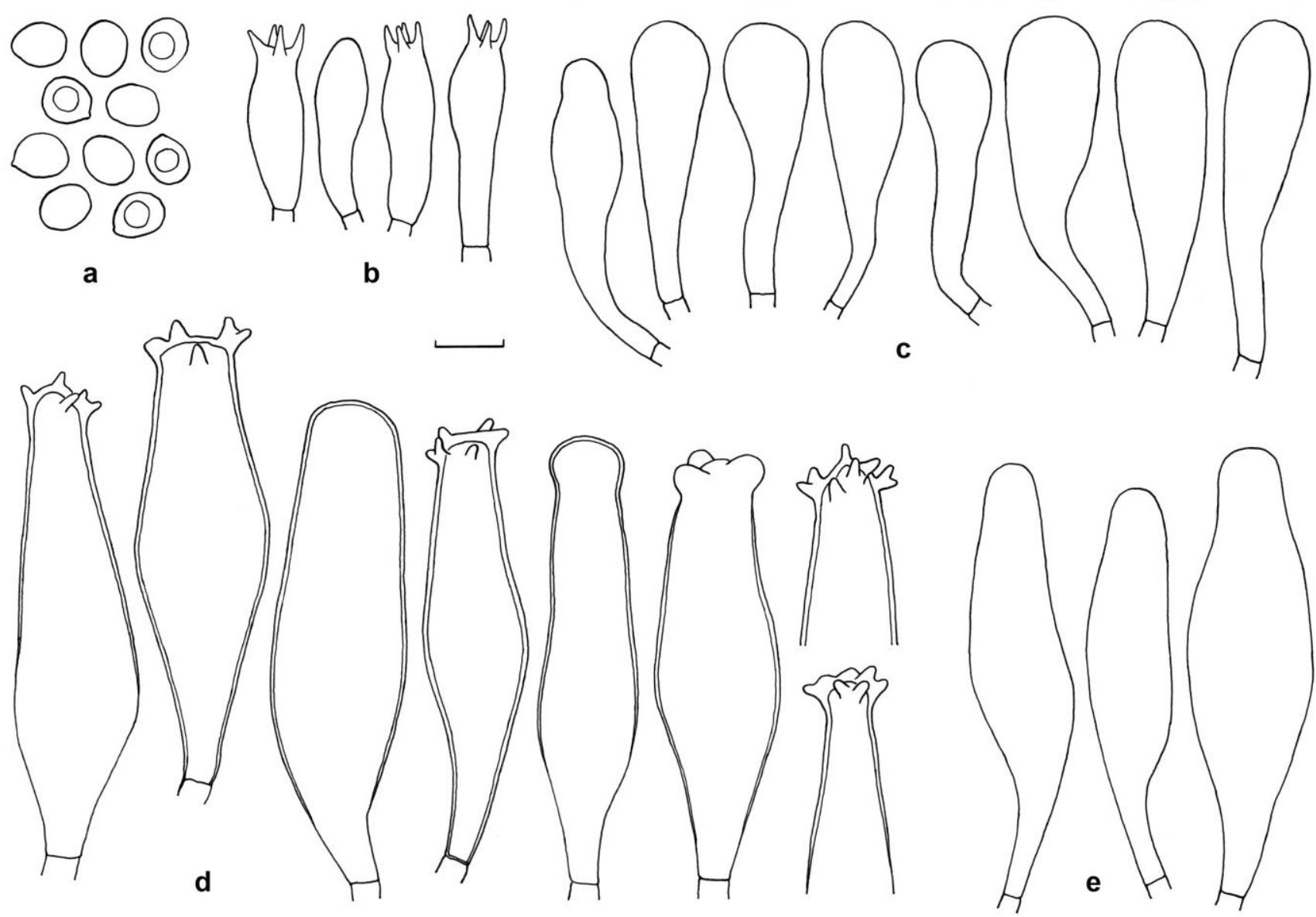

Figure 8 - Micromorphological features of Pluteus albostipitatus (DED 8205). a Basidiospores. b Basidia and basidiole. c Cheilocystidia. d Pleurocystidia (DED 8205). e Pleurocystidia (DED 8220). Scale bar $=10 \mu \mathrm{m}$

Material examined - AFRICA. São Tomé, Macambrara radio antenna area, N00 $16.557^{\prime}$, E06 36.326', elev. 1300 m, 11 April 2008, coll. by D.E. Desjardin, DED 8205 (MG968801, SFSU); same location, 25 April 2006 (material lost in transit); São Tomé, along main road (EN-2) on south side of island at N00 $12.126^{\prime}$, E06 42.362', 13 April 2008, coll. by D.E. Desjardin, DED 8220 (MG968802, SFSU).

Notes - Pluteus albostipitatus as represented in São Tomé is characterized by basidiomes with a dark brown, fibrillose-punctate, distinctly striate pileus, a solid, cylindrical white stipe, relatively large, subglobose to broadly ellipsoid basidiospores with mean $7.5 \times 6.6 \mu \mathrm{m}$, broadly clavate, thin-walled cheilocystidia, thick-walled, ventricose to fusoid-subcapitate pleurocystidia without or with 4-6 small, sometimes bifid apical horns, and an absence of caulocystidia and clamp connections. In combination, these features indicate placement in sect. Pluteus.

Pairwise comparisons of aligned, overlapping ITS sequences of the São Tomé specimens (DED 8205, DED 8220) with the top ten BLAST results indicate 99.4-99.9\% similarity to four specimens of Pluteus albostipitatus from DR Congo (HM562130) and Brazil (JQ065032, JQ801373, JQ065033). In addition, ITS sequences from the holotype specimens of $P$. phaeoleucus E. Horak (Goossens-Fontana 5102; HM562141) from the DR Congo, and P. densifibrillosus Menolli \& Capelari (SP393696 HM562159) from Brazil, showed 99.5\% and 99.3\% similarity, respectively, to the São Tomé specimens herein recognized as $P$. albostipitatus. Justo et al. (2011a, Fig. 1) provided a phylogeny of Pluteus sect. Pluteus based on ITS sequences in which the six sequences reported above from the DR Congo and Brazil formed a well-supported clade ( $\geq 90 \%$ BS, $\geq 0.95 \mathrm{PP}$ ) that they accepted as representing $P$. albostipitatus, indicating that $P$. phaeoleucus and $P$. densifibrillosus represent heterotypic synonyms of $P$. albostipitatus. Our ITS phylogeny (Fig. 6) places the São Tomé specimens firmly inside of the P. albostipitatus clade. 
A comparison of published descriptions of the latter three species suggests that there is extensive morphological variability within P. albostipitatus. Dennis (1953), Singer (1958), Horak (1978), Pegler (1983) report the pileus margin of $P$. albostipitatus as striate to sulcate, while that of P. phaeoleucus (Horak 1978) and P. densifibrillosus (Menolli \& Capelari 2010) are reported as non-striate. The pleurocystidia of $P$. albostipitatus are reported as lageniform, thin-walled (Horak 1978), fusoid with a subapical constriction and truncate apex, thin-walled (Pegler 1983), or ventricose with a constriction above the broadest portion and subcapitate-truncate, thin-walled (Singer 1958). In comparison, pleurocystidia of $P$. densifibrillosus were reported as slightly ventricose to lageniform with a rounded or sometimes constricted apex, thin-walled to slightly thick-walled (Menolli \& Capelari 2010), Horak (1978) reported the pleurocystidia as absent in $P$. phaeoleucus. Only Singer (1958) noted of the pleurocystidia "frequently tip truncate or with short obtuse or subacute small outgrowths." The São Tomé specimens encompass this range of pleurocystidia morphological variability. DED 8205 has numerous thick-walled pleurocystidia with small often bifid apical projections and others lacking projections with subapical constriction and truncate apex, while the pleurocystidia of DED 8220 are thin-walled, broadly clavate to lageniform, and lack apical projections.

Pluteus losulus Justo, in Justo, Minnis, Ghignone, Menolli, Capelari, Rodríguez, Malysheva, Contu \& Vizzini, Mycol. Progr. 10(4): 473. 2011.

Figs 9-10

Basionym: Pluteus cervinus var. ealaensis Beeli, Bull. Soc. R. Bot. Belg. 61(1): 81. 1928.

[nom. nov., non Pluteus ealaensis Beeli, Bull. Soc. R. Bot. Belg. 61(1): 80. 1928.]

Facesoffungi number: FoF04776

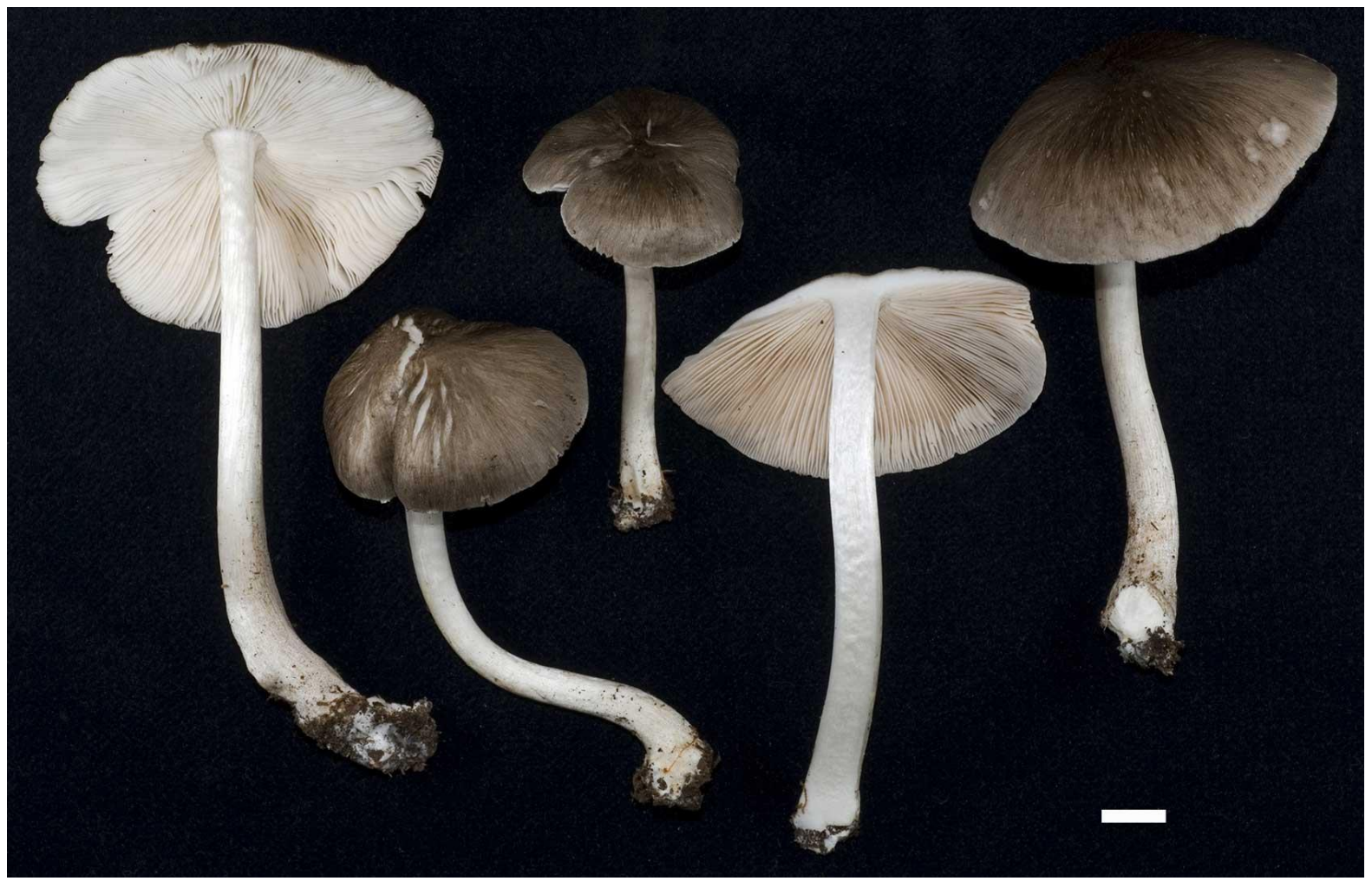

Figure 9 - Basidiomes of Pluteus losulus (DED 8313). Scale bar $=10 \mathrm{~mm}$

Pileus 40-80 $\mathrm{mm}$ diam, campanulate to broadly convex-umbonate, expanding to planoconvex with a shallow broad umbo; margin decurved, split in age, non-striate; surface dull, dry, radially streaked, appressed-fibrillose, greyish brown (7E3) with a dark greyish brown (7F4) disc and streaks. Context 2-4 mm thick, soft, white. Lamellae horizontal, free, close to crowded with 3 series of lamellulae, broad (5-8 mm), initially white, becoming greyish red (7B3). Stipe 50-110 $\times$ 
4-9 mm, central, terete, cylindrical above an enlarged base, solid, pliant; surface dull, dry, glabrous above, base appressed-fibrillose, white overall when young, in age base becoming greyish brown (7E3). Odor mild.

Basidiospores 6.5-8 $\times 5.5-6.5 \mu \mathrm{m}\left[\mathrm{x}_{\mathrm{m}}=7 \pm 0.51 \times 6 \pm 0.32 \mu \mathrm{m}, \mathrm{Q}=1.1-1.3, \mathrm{Q}_{\mathrm{m}}=1.17 \pm\right.$ $0.03, \mathrm{n}=20, \mathrm{~s}=1]$, subglobose to ovoid, smooth, subhyaline, inamyloid, thick-walled $(-0.5 \mu \mathrm{m})$; pinkish brown in deposit. Basidia 28-32 × 8-9.5 $\mu \mathrm{m}$, clavate to utriform, hyaline, 4-spored. Basidioles clavate. Lamellar edge sterile. Cheilocystidia 42-52 $\times 7-13 \mu \mathrm{m}$, clavate to subclavate, hyaline, inamyloid, thin-walled. Pleurocystidia common, 46-65 $\times 16-25 \mu \mathrm{m}$, ventricose to utriform, cornute, with 3-4 apical, straight to recurved hooks, hyaline, thick-walled $(-2 \mu \mathrm{m})$, seldom bifid with 1-2 apical hooks per arm. Pileipellis a cutis of repent hyphae 3.5-10 $\mu \mathrm{m}$ diam, cylindrical, hyaline or with brown cytoplasmic pigments, inamyloid, non-incrusted, non-gelatinous, thin-walled; terminal cells undifferentiated or slightly narrowed. Pileus trama interwoven; hyphae similar to pileipellis hyphae but all hyaline. Lamellar trama hyphae $2.5-10 \mu \mathrm{m}$ diam, cylindrical, hyaline, thin-walled. Stipitipellis a cutis of repent hyphae 5-14 $\mu \mathrm{m}$ diam, cylindrical, hyaline or with brown cytoplasmic pigments, non-incrusted, non-gelatinous, thin-walled; terminal cells undifferentiated. Caulocystidia absent. Clamp connections present in all tissues.

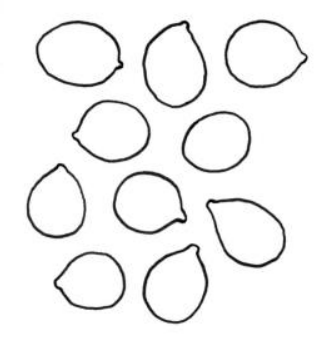

a

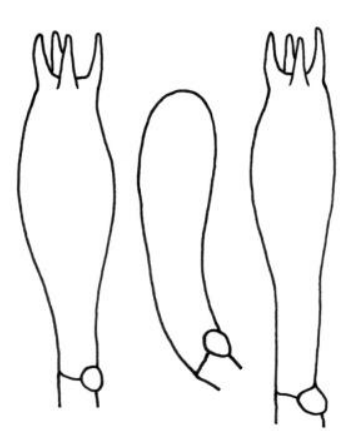

b

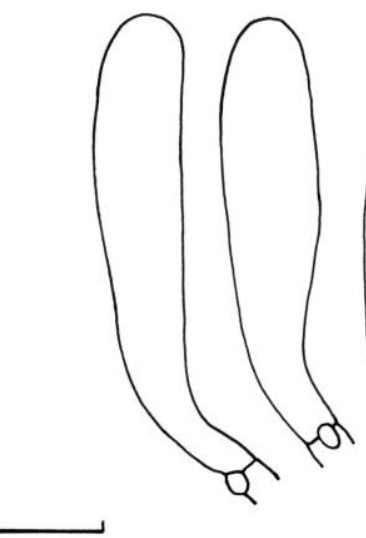

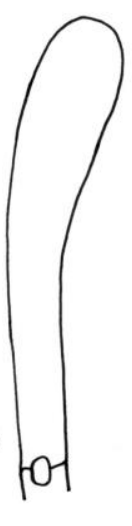
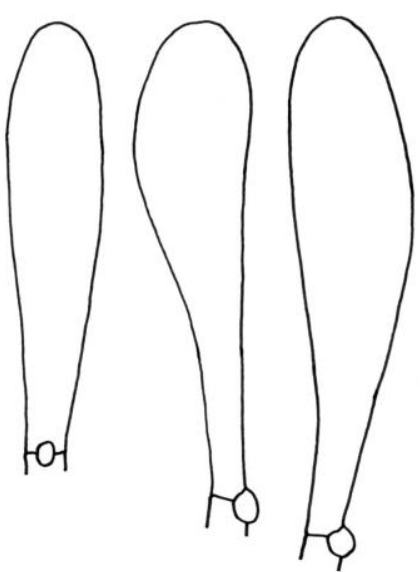

C
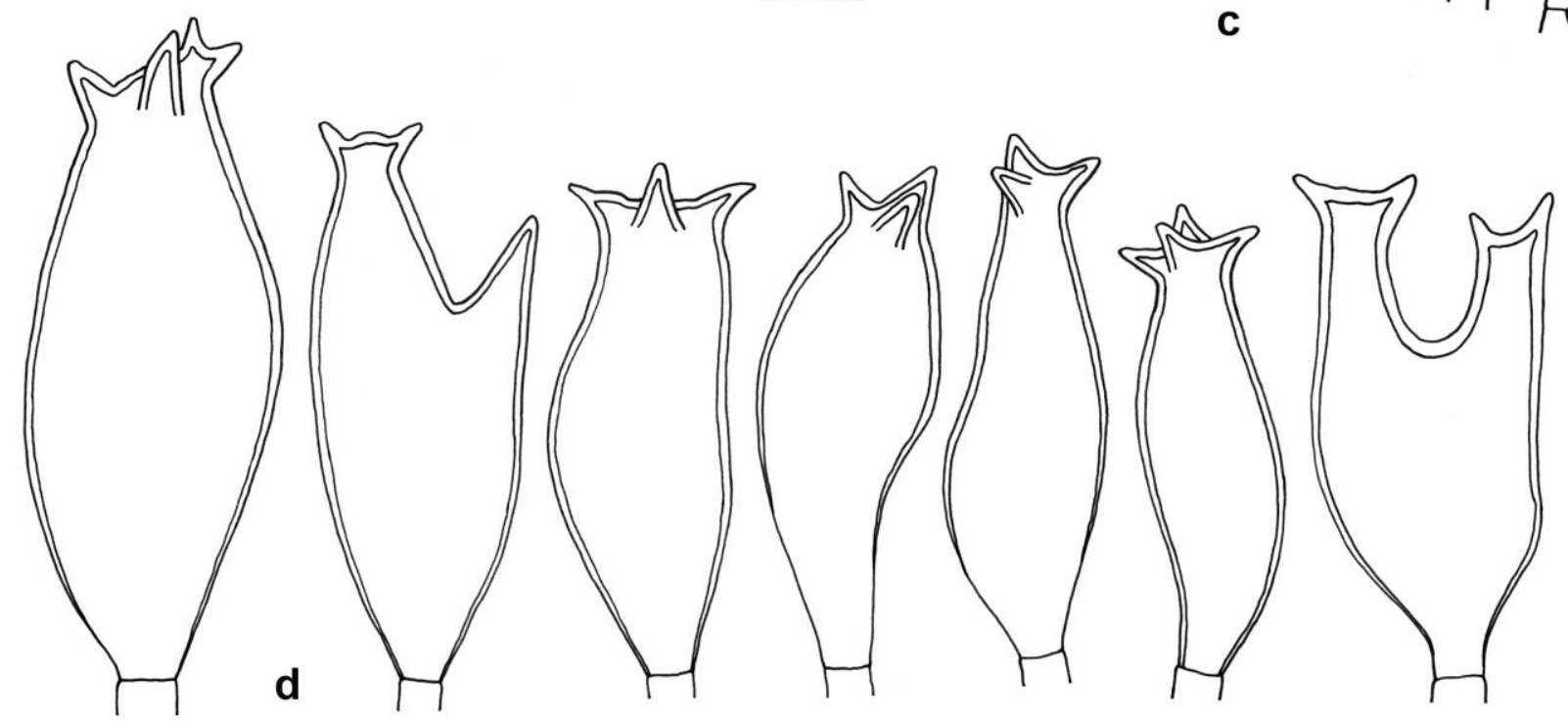

Figure 10 - Micromorphological features of Pluteus losulus (DED 8313). a Basidiospores. b Basidia and basidiole. c Cheilocystidia. d Pleurocystidia. Scale bar $=10 \mu \mathrm{m}$

Habitat and known distribution - Solitary, scattered on very rotten wood in coastal secondary forest. Africa (DR Congo, Príncipe).

Material examined - AFRICA. Príncipe, east side of island at N01 ${ }^{\circ} 35.728^{\prime}, \mathrm{E}^{\circ} 7^{\circ} 25.263^{\prime}, 23$ 
April 2008, coll. by B.A. Perry and D.E. Desjardin, DED 8313 (MG968803, SFSU).

Notes - Pluteus losulus is characterized by a campanulate, appressed-fibrillose, dark greyish brown pileus, white to greyish brown, glabrous stipe, subglobose basidiospores with mean $7 \times 6$ $\mu \mathrm{m}$, clavate, thin-walled cheilocystidia, apically hooked, thick-walled pleurocystidia, a cutis-type pileipellis and stipitipellis with undifferentiated terminal cells, abundant clamp connections, and growth on rotten wood. In combination, these features indicate placement in sect. Pluteus.

Pluteus losulus was originally described by Beeli (1928) as P. cervinus var. ealaensis Beeli, from material collected by Mme. Goossens-Fontana in the DR Congo. Horak (1978) included it in his treatment of Pluteus from Central Africa as P. atricapillus var. ealaensis Beeli, but without formal transfer to that species. It was elevated to species rank by Justo (Justo et al. 2011a), requiring a new name (non $P$. ealaensis Beeli, based on a different type). The new name reflects "losulu", the indigenous name for the species in the DR Congo. Our material from Príncipe matches quite nicely with the description provided by Horak (1978), based in part on analysis of the holotype specimen. Pluteus losulus is similar to P. cervinus, but the latter differs in forming ellipsoid basidiospores and in lacking clamp connections.

Pairwise comparisons of aligned, overlapping ITS sequences of the São Tomé specimen (DED 8313) with the top ten BLAST results indicate $100 \%$ similarity to a Goossens-Fontana specimen of P. losulus (HM562129) from the DR Congo. Our ITS phylogeny (Fig. 6) and that of Justo et al. (2011a) place P. losulus as sister to a clade composed of P. atromarginatus (Konrad) Kühner and a single sequence of $P$. atropungens A.H. Sm. \& Bartelli.

\section{Sect. Celluloderma Fayod}

Pluteus hirtellus Desjardin \& B.A. Perry, sp. nov.

Figs $12-13$

Mycobank: MB824541; Facesoffungi number: FoF04781

Holotype - AFRICA. São Tomé, Shipwreck Cove, along main road (EN-1) on north side of island at $18.25 \mathrm{~km}$ marker, N00 23.687', E06 36.702', 17 April 2008, coll. by B.A. Perry and D.E. Desjardin, DED 8259 (SFSU).

Etymology - hirtellus $(\mathrm{L})=$. shaggy, referring to the pileus surface.

Diagnosis - Pileus 23-35 mm diam, plano-convex, depressed in age, striatulate; surface dull, dry, disc shaggy, with tiny fibrillose scales, furfuraceous to subglabrous elsewhere; disc and scales dark brown (6F5-8), margin greyish brown (7E3-4) or paler. Context 1-2 mm thick, soft, dingy white. Lamellae free, close with 3 series of lamellulae, broad (3-5 mm), greyish red (8C4-5). Stipe $12-40 \times 2-3 \mathrm{~mm}$, central, terete, cylindrical, solid; surface dull, dry, glabrous or with a few silky fibrils, pure white overall.

Basidiospores 4.5-6 $\times 4.2-5.5 \mu \mathrm{m}\left[\mathrm{x}_{\mathrm{m}}=5.3 \pm 0.40 \times 4.96 \pm 0.29 \mu \mathrm{m}, \mathrm{Q}=1.0-1.1, \mathrm{Q}_{\mathrm{m}}=1.07\right.$ $\pm 0.04, \mathrm{n}=25, \mathrm{~s}=1]$, globose to subglobose, smooth, subhyaline, inamyloid, thick-walled $(-0.5$ $\mu \mathrm{m})$. Basidia 24-26 $\times 6.5-7 \mu \mathrm{m}$, clavate to subutriform, 4-spored, unclamped. Basidioles clavate to subclavate. Lamellar edge sterile. Cheilocystidia $25-48 \times 10-20 \mu \mathrm{m}$, broadly clavate to ventricose or vesiculose, seldom lageniform, hyaline, thin-walled. Pleurocystidia scattered, 35-60 × 14-24 $\mu \mathrm{m}$, clavate, rarely ventricose, hyaline, thin-walled. Pileipellis a cutis to trichodermium; hyphae 4$8(-10) \mu \mathrm{m}$ diam, repent, cylindrical, hyaline or with brown cytoplasmic pigments, non-incrusted, non-gelatinous; terminal cells over disc clustered, erect, elsewhere repent to suberect, 48-115 $\times 8$ $16 \mu \mathrm{m}$, fusoid to fusoid-ventricose, acute, seldom clavate or lageniform, with brown cytoplasmic pigments, thin-walled. Pileus trama hyphae interwoven, 4.5-10 $\mu \mathrm{m}$ diam, cylindrical, hyaline, nongelatinous, thin-walled; with numerous refractive oleiferous hyphae interspersed. Lamellar trama hyphae 2.5-8 $\mu \mathrm{m}$ diam, cylindrical, hyaline, non-gelatinous, thin-walled. Stipitipellis a cutis of repent hyphae 5-12 $\mu \mathrm{m}$ diam, cylindrical, hyaline, inamyloid, non-incrusted, non-gelatinous, thinwalled. Caulocystidia absent. Clamp connections absent in all tissues.

Habitat and known distribution - Solitary on decaying wood in coastal secondary forest. Africa (São Tomé).

Material examined - AFRICA. São Tomé, Shipwreck Cove, along main road (EN-1) on north 
side of island at $18.25 \mathrm{~km}$ marker, N00 23.687', E06 36.702', 17 April 2008, coll. by B.A. Perry and D.E. Desjardin, DED 8259 (MG968804, SFSU).

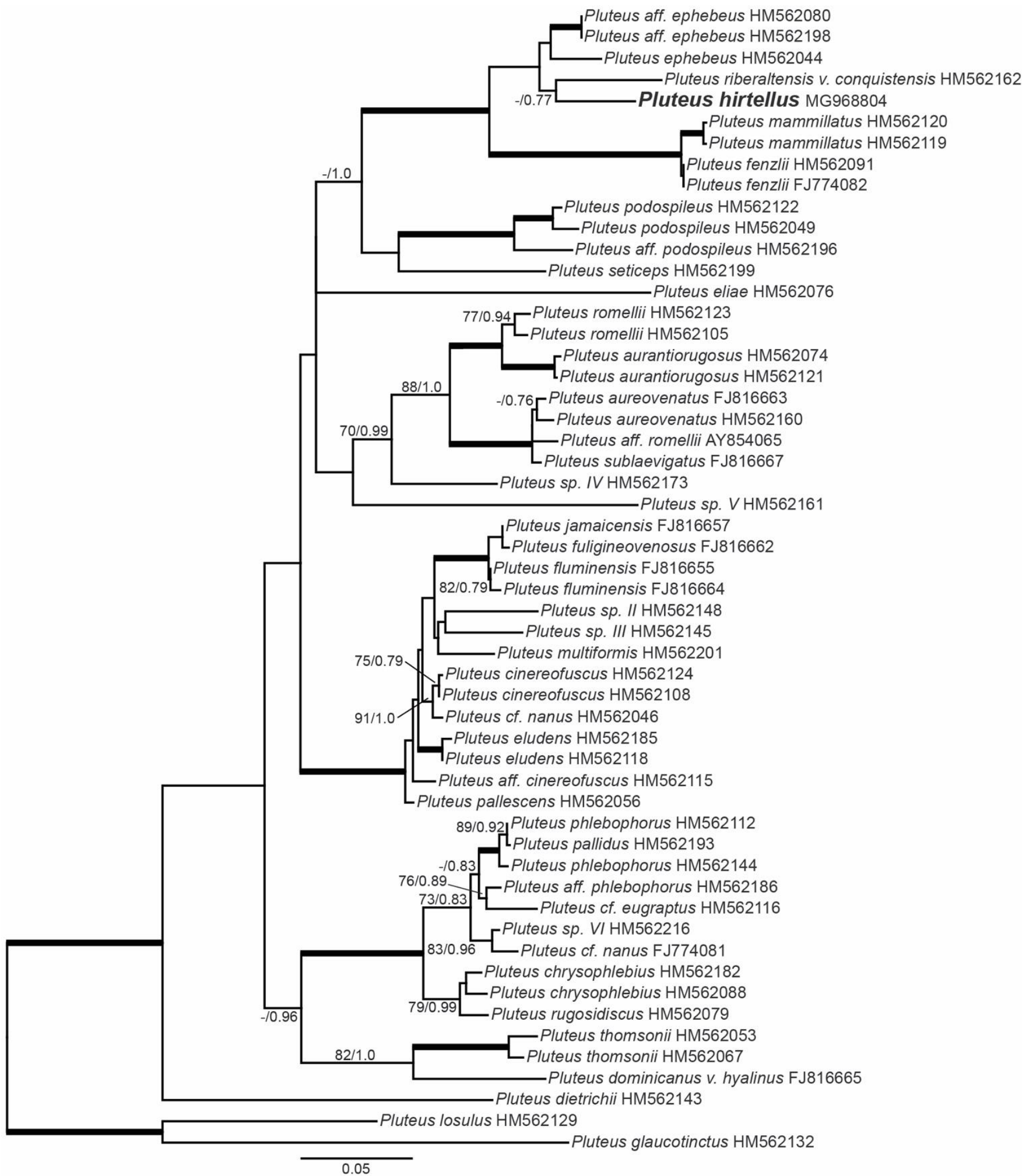

Figure 11 - Maximum likelihood phylogeny of Pluteus sect. Celluloderma based on ITS sequence data $(-\ln L=6516.135752)$. Sequences of species from São Tomé are indicated in bold type. Values separated by/refer to nonparametric ML bootstrap proportions and Bayesian posterior probabilities. Only values greater than 70/0.70 are shown (- designates a value below $70 \%$ or 0.70 ). Nodes receiving support values greater than 90/0.95 are highlighted in bold. 
Notes - Pluteus hirtellus is characterized by a relatively small pileus with dark brown minutely scaly disc, a pure white, solid stipe, small, globose to subglobose basidiospores with mean $5.3 \times 5.0 \mu \mathrm{m}$, broadly clavate to ventricose cheilocystidia, thin-walled, clavate pleurocystidia, a cutis to trichodermium-type pileipellis with long, fusoid-acute, brown terminal cells, an absence of caulocystidia and clamp connections, and growth on rotten wood in a coastal secondary forest. In combination, these features indicate placement in sect. Celluloderma of Justo et al. (2011a) or sect. Villosi of Vellinga \& Schreurs (1985).

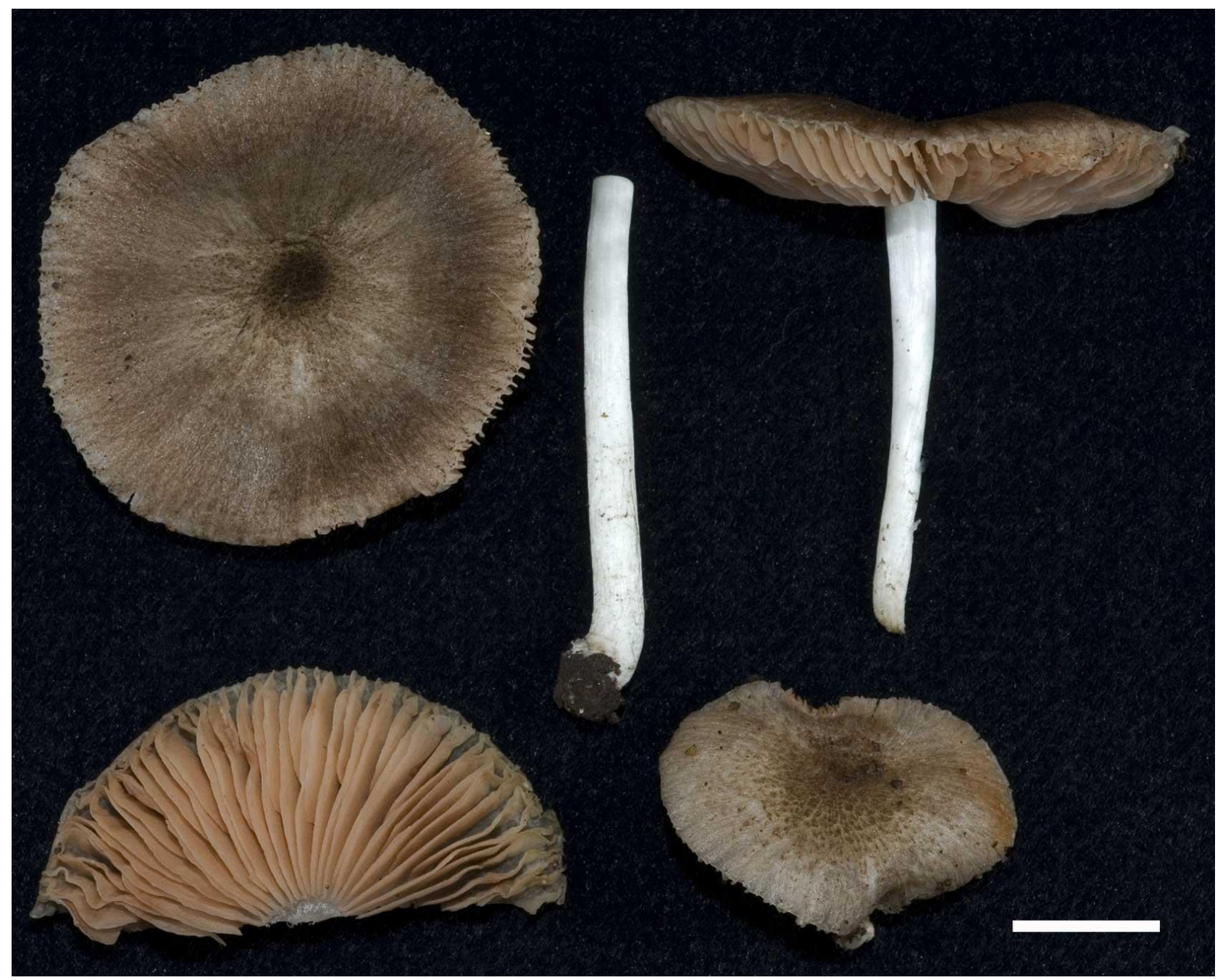

Figure 12 - Basidiomes of Pluteus hirtellus (DED 8259, Holotype). Scale bar $=10 \mathrm{~mm}$

Pluteus hirtellus differs only subtly from the protologue of P. riberaltensis (Singer 1958), described from Bolivia, in forming pileipellis terminal cells that are more acutely fusiform. Basidiome features, basidiospore and cystidia size and shape match nicely, although ITS data are quite distinct (see below and Fig. 11). The new species shows morphological similarities to $P$. ephebeus (Fr.) Gillet, P. hispidulus (Fr.) Gillet, and P. escharites (Berk. \& Broome) Sacc. Pluteus ephebeus forms larger basidiomes with pileus $35-70 \mathrm{~mm}$ diam, a stipe $45-90 \times 4-8 \mathrm{~mm}$ covered with brown fibrils, larger broadly ellipsoid basidiospores $(5.5-8.0 \times 4.5-6.0 \mu \mathrm{m})$, and utriform to fusiform or lageniform hymenial cystidia (Vellinga \& Schreurs 1985, Vellinga 1990). Pluteus hispidulus forms a conical to applanate-umbonate pileus, larger broadly ellipsoid basidiospores $(6-8 \times 5-6 \mu \mathrm{m})$, and lacks pleurocystidia (Vellinga 1990). Pluteus escharites, described from Sri Lanka and reported from Africa (Pegler 1977, 1986), shares basidiome macrofeatures, small subglobose basidiospores and cheilocystidia shape, but differs in lacking pleurocystidia which are abundant and conspicuous in P. hirtellus. 
Pairwise comparisons of aligned, overlapping ITS sequences of Pluteus hirtellus (DED 8259) with the top ten BLAST results indicate $98.6 \%$ similarity to three specimens from India determined as Pluteus sp. (KR002882, KR002899, KT186192); 92.4\% similarity to two specimens of Pluteus aff. ephebeus from Illinois (USA; JQ065025, JQ065026); $92.3 \%$ similarity to a specimen of $P$. ephebeus from Spain (HM562044); and 92.0-92.2\% similarity to three specimens of $P$. aff. ephebeus from Europe (HM562198, HM562080, KM983671). The ITS sequence of P. hirtellus is only $88.2 \%$ similar to that of $P$. riberaltensis var. conquistensis (HM562162). In our ITS phylogeny (Fig. 11), P. hirtellus is on a relatively long branch sister to P. riberaltensis var. conquistensis (from Brazil), and together sister to P. ephebeus.

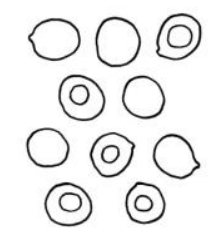

a

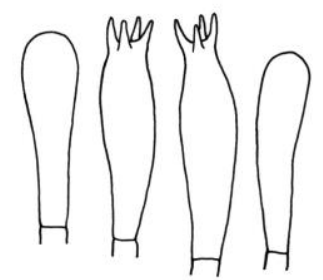

b
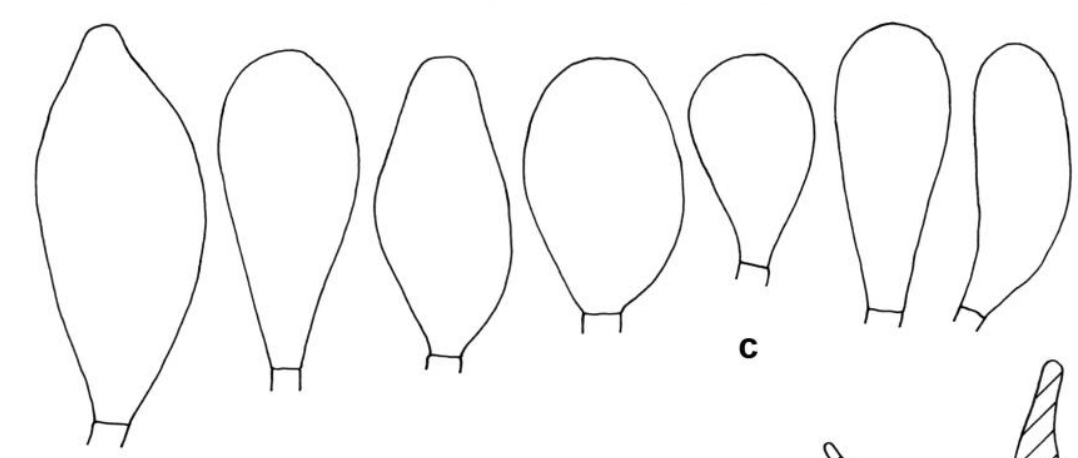

C
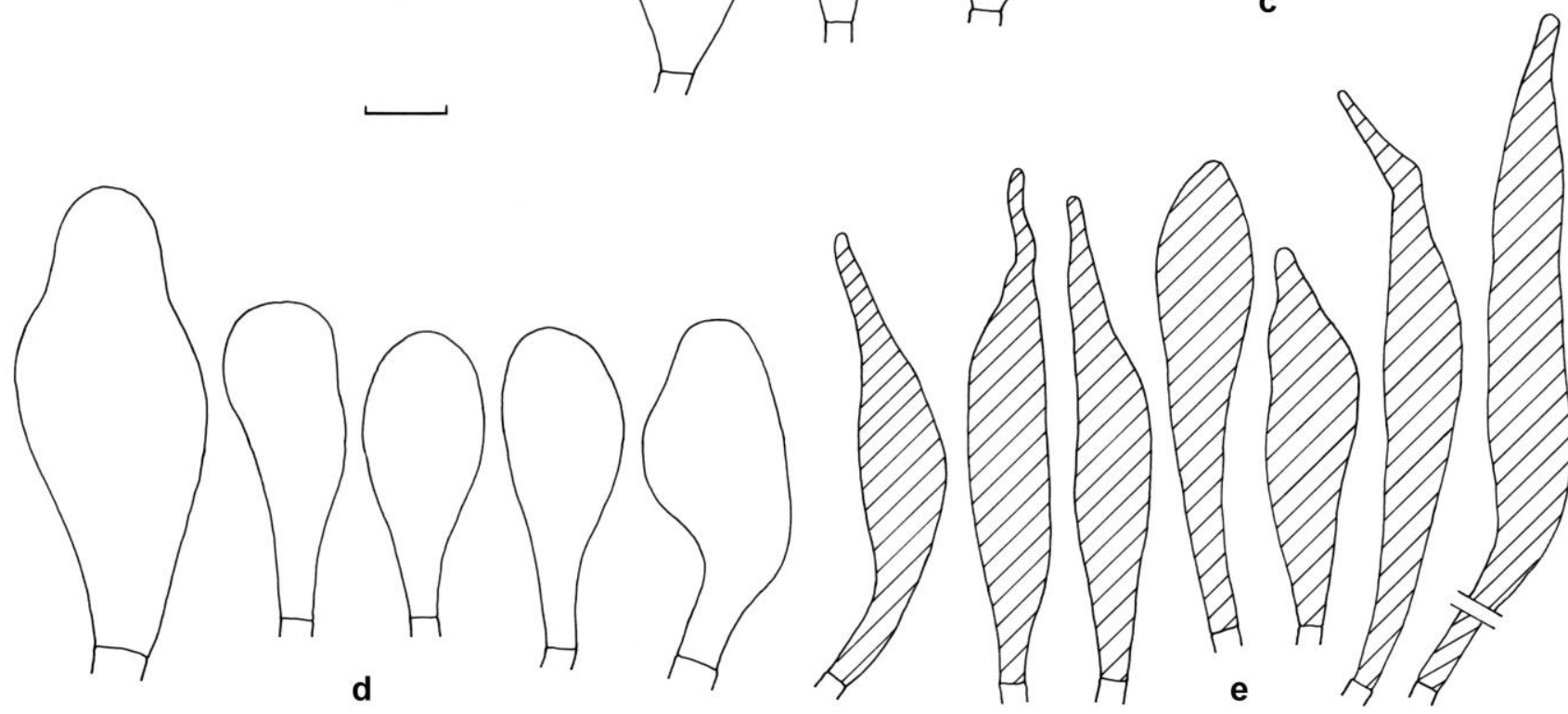

Figure 13 - Micromorphological features of Pluteus hirtellus (DED 8259, Holotype). a Basidiospores. b Basidia and basidioles. c Cheilocystidia. d Pleurocystidia. e Pileipellis terminal cells. Scale bar $=10 \mu \mathrm{m}$

\section{Acknowledgments}

We thank Dr. Robert C. Drewes (California Academy of Sciences) who continues to initiate, coordinate and lead multi-organism biotic surveys on São Tomé and Príncipe; Eng. Arlindo de Ceita Carvalho, Director General of the Ministry of Environment, Victor Bonfim, Salvador Sousa Pontes and Danilo Barbero for permission to collect and export specimens for study. We are indebted to Société de Conservation et Développement for logistics and housing support, especially the wonderful staffs of Omali Lodge and Bom Bom Island. We are grateful for the support and cooperation of Bastien Loloumb of Zuntabawe and Faustino Oliviera, former Director of the botanical garden at Bom Sucesso. We were assisted in the field by Jose Ramos Maria Vital Pires on Príncipe and by Quintino Quade Cabral, Martinho Nascimiento and Jose Clara on São Tomé, and in the lab at Cal State East Bay by Jonathan del Rosario. For continuing support, we are most grateful to Ned Seligman, Quintino Quade Cabral and Roberta dos Santos of STePUP. We are grateful to the College of Science and Engineering at San Francisco State University for partial 
funding to support travel to São Tomé and Príncipe, and to the G. Lindsay Field Research Fund of the California Academy of Sciences (CAS) for financially supporting the expedition in 2006 and the Hagey Research Venture Fund (CAS) in 2008. Lastly, we are especially grateful to Roderick C.M. Hall, Coleman P. Burke and William K. Bowes Jr. whose generous philanthropy has supported our research on São Tomé and Príncipe.

\section{References}

Beeli M. 1928 - Contribution a l'étude de la Flore mycologique du Congo: VI: Fungi Goossensiani, Agaricacées, Rhodosporées. Bulletin de la Société Royale de Botanique de Belgique 61(1), 78-107.

Berkeley MJ, Broome CE. 1871 - The fungi of Ceylon. Journal of the Linnean Society 11, 494567.

Dennis RWG. 1953 - Les Agaricales de l'Ille de la Trinité: Rhodosporae-Ochrosporae. Bulletin de la Société Mycologique de France. 69(2), 145-198.

Desjardin DE, Perry BA. 2009 - A new species of Phallus from São Tomé, Africa. Mycologia 101(4), 543-545. DOI: 10.3852/08-166

Desjardin DE, Perry BA. 2015a - A new species of Scytinopogon from the island of Príncipe, Republic of São Tomé and Príncipe, West Africa. Mycosphere 6(4), 433-440. DOI: 10.5943/mycosphere/6/4/5

Desjardin DE, Perry BA. 2015b - Clavarioid fungi and Gasteromycetes from the Republic of São Tomé and Príncipe, West Africa. Mycosphere 6(4), 515-531. DOI: 10.5943/mycosphere/6/5/2

Desjardin DE, Perry BA. 2016 - Dark-spored species of Agaricineae from Republic of São Tomé and Príncipe, West Africa. Mycosphere 7(3), 359-391. DOI: 10.5943/mycosphere/7/3/8

Desjardin DE, Perry BA. 2017 - The gymnopoid fungi (Basidiomycota, Agaricales) from Republic of São Tomé and Príncipe, West Africa. Mycosphere 8(9), 1317-1391. DOI: 10.5943/mycosphere/8/9/5

Gardes M, Bruns TD. 1993 - ITS primers with enhanced specificity for basidiomycetes application to the identification of mycorrhizae and rusts. Molecular Ecology 2, 113-118.

Horak E. 1977 - Neue zaïrische Arten aus der Gattung Pluteus Fr. Bulletin du Jardin Botanique National de Belgique 47, 87-89.

Horak E. 1978 - Flore illustrée des champignons d'Afrique centrale. Fasc 6: Pluteus (Pluteaceae). National Botanical Garden of Belgium, Meise. pp 107-118.

Huelsenbeck JP, Ronquist F. 2001 - MrBayes: Bayesian inference of phylogeny. Bioinformatics 17, 754-755.

Justo A, Minnis AM, Ghignone S, Menolli JrN et al. 2011a - Species recognition in Pluteus and Volvopluteus (Pluteaceae, Agaricales): morphology, geography and phylogeny. Mycological Progress 10(4), 453-479.

Justo A, Vizzini A, Minnis AM, Menolli JrN et al. 2011b - Phylogeny of the Pluteaceae (Agaricales, Basidiomycota): taxonomy and character evolution. Fungal Biology 115, 1-20. DOI: 10.1016/j.funbio.2010.09.012

Kornerup A, Wanscher JH. 1978 - Methuen Handbook of Colour. 3rd ed. Eyre Methuen, London.

Maddison WP, Maddison DR. 2015 - Mesquite: a modular system for evolutionary analysis. Version 3.04 (http://mesquiteproject.org).

Menolli JrN, Capelari M. 2010 - Notes on Pluteus (Pluteaceae, Agaricvales) from Brazil including two new species and a new record. Mycologia 102(3), 697-707.

Menolli JrN, Justo A, Arrillaga P, Pradeep CK et al. 2014 - Taxonomy and phylogeny of Pluteus glaucotinctus sensu lato (Agaricales, Basidiomycota), a multicontinental species complex. Phytotaxa 188(2), 78-90. DOI: 10.11646/phytotaxa.188.2.2

Miller MA, Pfeiffer W, Schwartz T. 2010 - "Creating the CIPRES Science Gateway for inference of large phylogenetic trees" in Proceedings of the Gateway Computing Environments 
Workshop (GCE), 14 Nov. 2010, New Orleans, LA pp 1-8.

Pegler DN. 1977 - A preliminary agaric flora of East Africa. Kew Bulletin Additional Series 6, $1-615$.

Pegler DN. 1983 - Agaric flora of the Lesser Antilles. Kew Bulletin Additional Series 9, 1-668.

Pegler DN. 1986 - Agaric flora of Sri Lanka. Kew Bulletin Additional Series 12, 1-519.

Perry BA, Hansen K, Pfister DH. 2007 - A phylogenetic overview of the family Pyronemataceae (Ascomycota, Pezizales). Mycological Research 111, 549-571.

Pradeep CK, Vrinda KB. 2006 - New and noteworthy species of Pluteus (Pluteaceae, Agaricales) from Kerala State, India. Persoonia 19(1), 95-99.

Pradeep CK, Justo A, Vrinda KB, Shibu VP. 2012 - Two new species of Pluteus (Pluteaceae, Agaricales) from India and additional observations on Pluteus chrysaegis. Mycological Progress 11, 869-878. DOI 10.1007/s11557-011-0801-y

Ronquist F, Huelsenbeck JP. 2003 - MrBayes 3: Bayesian phylogenetic inference under mixed models. Bioinformatics 19, 1572-1574.

Singer R. 1958 - Monographs of South American Basidiomycetes, especially those of the east slope of the Andes and Brazil. 1. The genus Pluteus in South America. Lloydia 21(4), 195299.

Singer R. 1986 - The Agaricales in Modern Taxonomy. 4th Ed. Koeltz Scientific Books, Koenigstein, Germany. 981 p.

Stamatakis A. 2014 - RAxML Version 8: A tool for Phylogenetic Analysis and Post-Analysis of Large Phylogenies. Bioinformatics 10.1093/bioinformatics/btu033.

Swofford DL. 2002 - PAUP*. Phylogenetic Analysis Using Parsimony (*and Other Methods). Version 4. Sinauer Associates, Sunderland, Massachusetts.

Vellinga EC. 1990 - Pluteaceae. In: Bas C, Kuyper TH, Noordeloos ME, Vellinga EC, eds. Flora Agaricina Neerlandica 2, 31-55.

Vellinga EC, Schreurs J. 1985 - Notulae ad floram Agaricinam Neerlandicam - VIII. Persoonia 12(4), 337-373.

White TJ, Bruns T, Lee S, Taylor J. 1990 - Amplification and direct sequencing of fungal ribosomal RNA genes for phylogenetics. In: Innis MA, Gelfand DH, Sninsky JJ, White TJ, eds. PCR Protocols: a guide to methods and applications. San Diego: Academic Press. p. 315-322. 